\title{
Allocation of time and child socio-emotional skills
}

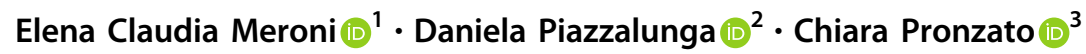

Received: 1 July 2020 / Accepted: 30 July 2021 / Published online: 1 September 2021

(c) The Author(s) 2021

\begin{abstract}
In this study, we investigate the effect of time allocation on children's non-cognitive development, using data from the Millennium Cohort Study (UK) and focusing on children aged 7 and 11 years. We classify the time spent outside of school into seven groups of activities and evaluate their impact on five socio-emotional skills drawn from the Strength and Difficulties Questionnaire, leveraging the data's panel structure. We subsequently test the robustness of our estimates against endogeneity issues. Time spent on sports, studying, reading, tidying up and active time with parents have beneficial effects, while video-screen time and extra hours at school have harmful effects.
\end{abstract}

JEL codes $\mathrm{J} 13 \cdot \mathrm{J} 24 \cdot \mathrm{I} 24 \cdot \mathrm{D} 10$

Keywords Child time use $\cdot$ Extra-curricular activities $\cdot$ Non-cognitive development Socio-emotional skills $\cdot$ Omitted variable bias $\cdot$ Reverse causality

\section{Introduction}

Increasingly, scientists from different disciplines are studying how childhood conditions contribute to individual development regarding educational attainment, social behaviour, labour market prospects and health conditions. Both families and school play a vital role in this process by bolstering or harming children's skills, which are

Supplementary information The online version contains supplementary material available at https://doi. org/10.1007/s11150-021-09580-9.

Elena Claudia Meroni

elena.meroni@ec.europa.eu

1 European Commission, Joint Research Centre (JRC), Via E. Fermi 2749, 21027 Ispra, Italy

2 Department of Economics and Management, University of Trento, IZA and CHILD-Collegio Carlo Alberto, Via V. Inama, 5, 38122 Trento, Italy

3 Department of Economics and Statistics EST, University of Turin, IZA and Collegio Carlo Alberto, Lungo Dora Siena 100, 10053 Torino, Italy 
predictors of later outcomes in several domains (Lundberg, 1993; Hill et al., 2001; Case et al., 2005; Leschied et al., 2008; Francesconi et al., 2010).

The effects of attending formal childcare on younger children have been thoroughly investigated, as have the effects of school quality on older children. ${ }^{1}$ However, children are also exposed to other development opportunities. The hours between the end of school and bedtime are often filled with various activities that can promote different skills. These activities may be more or less structured (e.g. participating in team sports versus playing freely in the park), geared towards educational enrichment or social activities, and they can be performed alone, with other children (friends, siblings, cousins) or adults (parents, grandparents, instructors). Understanding the effects of such activities is important because they contribute to children's development and may be possible sources of inequality among children from different socio-economic backgrounds. Notably, it has been shown that inequality in socio-emotional skills has increased in the UK over the past 30 years, with the socioeconomic status of mothers being a significant contributing factor (Attanasio et al., 2020).

As part of the broader discussion of the importance of childhood conditions for an individual's development, the key question central to our analysis is how time allocation influences children's non-cognitive development. Particularly, we study the effects of time use on emotional symptoms, conduct problems, hyperactivity/ inattention, peer relationship problems and prosocial behaviour at ages 7 and 11, using data from the Millennium Cohort Study (MCS) (UK). We consider time spent outside regular school time: with parents, in extra-curricular activities (music, sports, extra classes) as well as less structured activities, such as going to the library, attending religious services, reading, watching $\mathrm{TV}$, playing electronic games and performing small chores around the house, such as tidying up or caring for pets.

To study the effects of time allocation on children's non-cognitive outcomes at ages 7 and 11, we apply a cumulative value-added model. Subsequently, we test the sensitivity of our results to possible endogeneity issues resulting from unobserved variables, reverse causality and measurement error due to the inclusion of past behavioural indicators in the model. To handle the omitted variable bias, we apply a method developed by Oster (2019) to produce bias-adjusted estimates and bind the coefficients of interest in the presence of such omitted variable bias. To address reverse causality, we leverage the panel dimension of the data, including only lagged activities. The bias due to the inclusion of lag outcomes is handled through an instrumental variable approach. Finally, we complement our analysis with a fixedeffects approach, which allows us to consider unobservable time-invariant characteristics but does not permit estimation of age-specific effects. The results show that time spent on sports, studying, reading, doing small chores around the house and time spent actively with parents are beneficial for the development of children's socio-emotional skills, while video-screen time and extra hours spent at school are detrimental. To the best of our knowledge, this is the first study showing that the allocation of children's time is important not only for cognitive but also for non-

\footnotetext{
1 Some references to studies on the effects of formal childcare and school quality: Card \& Krueger (1992); Duncan \& Magnuson (2013) (review); Elango et al. (2016) (review); Brilli et al. (2016); Del Boca et al. (2018); Rivkin et al. (2005); Ding \& Lehrer (2007); Deming et al. (2014).
} 
cognitive development, in line with some of the results on parental inputs (Moroni et al., 2019) and with studies on the impact of individual activities (Hille \& Schupp, 2015).

Although we explored possible heterogeneities in the effects of some child characteristics (socio-economic status, gender, nationality and family composition), we found no significant differences.

This study contributes to the literature in three specific ways: focusing on noncognitive outcomes (rather than cognitive ones); studying the effects of several activities (rather than a single activity); and considering activities conducted not only with parents but also independently and with other children.

Focusing on non-cognitive development is crucial and forms the basis of this study. The literature documents that these skills are at least as important as cognitive ones not only for future educational and labour market outcomes but also risky adolescent behaviour and health-related outcomes (Heckman \& Rubinstein, 2001; Cunha \& Heckman, 2008; Prevoo \& ter Weel, 2015; Attanasio et al., 2020). Noncognitive skills also influence learning abilities and cognitive development (Almlund et al., 2011). The seminal work by Heckman \& Rubinstein (2001) led empirical studies to investigate the impact of childhood conditions on non-cognitive development. Particularly, it has been shown that non-cognitive skills are improved by good parental investments such as income and material resources, cognitive stimulation, parental interpersonal skills, parenting style and breastfeeding (Cunha \& Heckman, 2008; Borra et al., 2012; Cunha et al., 2013; Heckman \& Kautz, 2013; Fletcher \& Wolfe, 2016; Doyle et al., 2017; Moroni et al., 2019).

Studying the relationship between time allocation and non-cognitive development is important because non-cognitive skills can be highly sensitive to the impact of extra-curricular activities. Qualitative studies have suggested that since the emphasis at school is on academic attainment, out-of-school activities provide children who perform poorly at school with opportunities to feel capable, thus increasing their selfesteem and wellbeing (Callanan et al., 2016). It also allows children to make and interact with new friends, and this may have possible consequences on social outcomes. Therefore, understanding if there is a link between time allocation and noncognitive development is highly relevant, as it could shape the way policy-makers and educational institutions intervene in designing the supply of such activities. Moreover, the increasing importance of extra-curricular activities may have different impacts according to socio-economic background, and thus can be a source of increased socio-emotional inequalities that call for intervention by policy-makers.

The second focus of this study is on the effects of several activities, whereas it is more common in the literature to find studies considering a single activity (e.g. reading, sport, music or computer and TV use). ${ }^{2}$ A few studies used data from

\footnotetext{
${ }^{2}$ Beneficial effects of reading, music and participating in religious activities are found in Anderson et al. (1988); Taylor et al. (1990); Hale et al. (2011); Kalb \& Van Ours (2014) [reading]; Hille \& Schupp (2015) [music]; Eccles et al. (2003); Mendolia et al. (2019) [religious activities]. Mixed results about the effects of sport (positive or no effect) are found in Lechner (2009); Pfeifer \& Cornelißen (2010); Rees \& Sabia (2010); Cuffe et al. (2017); Felfe et al. (2016); Ransom \& Ransom (2018). Mixed results are reported for computer and TV use (negative effects, no effect or positive effects for migrant children), see Zavodny (2006); Gentzkow \& Shapiro (2008); Munasib \& Bhattacharya (2010); Huang \& Lee (2010); Kearney \& Levine (2019); Hernæs et al. (2019) [TV]; Subrahmanyam et al. (2000); Fairlie \& Kalil (2017).
} 
children's time diaries to explore the full range of activities, such as the one by Hofferth \& Sandberg (2001), Fiorini \& Keane (2014) and Caetano et al. (2019). Hofferth \& Sandberg (2001) used data from the 1997 US Child Development Supplement to the Panel Study of Income Dynamics (PSID) (around 2000 children aged 0-12) and found that time devoted to learning activities such as reading is positively correlated with high school achievement, as is structured time spent playing sports or on social activities. Additionally, time spent eating meals with the family is associated with fewer behavioural problems. Fiorini \& Keane (2014) used time use diaries from the Longitudinal Study of Australian Children (around 1300 children aged 4-9) to consider the overall impact of time use and to study the tradeoff between the benefits of alternative activities. The result of their study is a ranking of activities from the most to the least beneficial: time spent on educational activities, particularly with parents, was the most productive for cognitive skill development. However, they found that non-cognitive skills are insensitive to alternative time allocations. Caetano et al. (2019) also used the time diaries from the Child Development Supplement of the 2002 and 2007 PSID to estimate the effect of family time inputs on cognitive skills, applying an exogeneity test developed by Caetano (2015). ${ }^{3}$ Their study provided a different classification of activities from those in previous studies (and our own), aggregating them into active and passive time with different individuals. They reported that active time with an adult family member (parents or grandparents) induces an increase in cognitive skills. ${ }^{4}$ Hofferth \& Sandberg (2001), Fiorini \& Keane (2014) and Caetano et al. (2019) represented the ideal benchmark for our study, but unluckily we do not have time use diaries at our disposal. This means that-despite considering a large set of different activities-we lack the data to evaluate the trade-off between them. The differences between our results and previous findings in the literature are discussed in the Results section.

The third contribution of this study is to consider the effects of time allocation beyond parental time on child development. Todd \& Wolpin (2007) used data from the National Longitudinal Survey of Youth to estimate the effect of parental and school inputs on child cognitive abilities. Parental input was represented by an index that considers parental stimulation and involvement and the toys and learning materials available. The results show that parental inputs have positive effects on children's cognitive development. The effect of parental time is also the focus of three studies using data from the Child Development Supplement to the Panel Study of Income Dynamics (US). Carneiro \& Rodriguez (2009) found that children (especially ages 3-6) who spend more time with their mothers perform better on cognitive tests. Hsin \& Felfe (2014) found that working mothers spend less time with their children, but only on unstructured activities, and what counts instead for child cognitive development and positive behaviour is the time spent engaging in educational activities together. Finally, Del Boca et al. (2017) considered the combined

\footnotetext{
${ }^{3}$ Unfortunately, the exogeneity test proposed by Caetano (2015) cannot be applied in our setting because of the metric of our independent variables: the test is particularly suitable for variables which have a bunching point, which is not our case.

${ }^{4}$ The authors also investigate the impact on non-cognitive skills. However, as the exogeneity test they use does not have enough power to detect endogeneity, they do not comment on these skills in the study, as they do not consider them as reliable.
} 
effect of spending time doing beneficial activities independently or together with their parents on children of different ages. They found that time spent independently on these activities in adolescence has a positive effect on cognitive outcomes, whereas time spent with the mother is more important for younger children.

Among the studies of parental time inputs, the most similar to this study regarding data and analysis techniques is Del Bono et al. (2016). Their study aimed to identify the effect of time spent with the mother (divided into recreational time and educational time) at the ages of 3,5 and 7 on children's cognitive skills and behavioural difficulties. The goal of our study is to investigate the effect of different uses of time, grouped into seven categories (among which is time spent with parents) on the noncognitive development of older children aged 7 and 11, ages at which time with parents is reduced and time increases in other activities. Furthermore, non-cognitive skills are treated separately and prosocial behaviour is also considered.

This study is organised as follows: Section 2 describes the MCS, the selection of the sample and the variables used throughout the analyses. Section 3 presents the methods employed for the empirical analysis. Section 4 contains the results and the robustness checks. Section 5 presents the conclusions.

\section{Data, sample selection and main variables of interest}

The MCS is a longitudinal survey that tracks the lives of a sample of about 19,000 babies born in the UK in 2000/2001. The survey was conducted in different waves: we use information from surveys for cohort-children aged about 9 months, 3, 5, 7 and 11 years old. The dataset has two considerable advantages: first, many of the questions and child indicators are repeated over time; second, it provides ample information about the child and the child's family from birth, which may provide important data to control for.

The initial wave one sample comprises 18,818 children, but around $10 \%$ of the sample is lost due to attrition at each new wave. We only consider children in families participating in the survey up to wave 4 or 5, when the children are 7 and 11 years old. Additionally, we exclude twins due to the possibility of different timings in their development with respect to single-birth children (Mowrer, 1954; Mittler, 1971). The sample is further restricted to children with non-missing information on the dependent variables. Our final samples comprise 10,570 children in wave 4 (children aged 7) and 9438 in wave 5 (children aged 11). Table 9 in the Appendix shows how the final samples analysed differ from the initial sample in wave one, due to attrition and sample selection. It turns out that the final samples include more educated and work-attached parents than the general population interviewed in wave one.

The MCS has repeated measurements of a child's non-cognitive outcomes and contains rich information about parental socio-economic background, employment status, childcare arrangements and specific parental inputs at various points in time. Of particular interest to this study are the variables reporting extra-curricular activities and indicators of the child's development and wellbeing when s/he is 5, 7 and 11 years old. We focus on non-cognitive outcomes, specifically child socio-emotional skills derived from the Strength and Difficulties Questionnaire (SDQ) included in the 
MCS, which highlights both positive and undesirable behaviours. ${ }^{5}$ As with most of the variables, the respondent to questions regarding activities and child socioemotional skills is virtually always the mother. ${ }^{6}$

Ideally, one would like to investigate the impact of activities on both cognitive and non-cognitive outcomes; however, in the MCS, no cognitive indicator is measured over the three waves, and between ages 7 and 11, none is measured over the two waves. Therefore, the empirical strategies would be different from the one implemented in the study, limiting the scope of comparison between results on cognitive and non-cognitive outcomes. Considering the dearth of studies on the relationship between activities and socio-emotional development, we found it more valuable and interesting to focus on non-cognitive outcomes.

The 25 items on the SDQ ask parents about the behavioural attributes of their child and measure five children's socio-emotional dimensions (emotional symptoms, conduct problems, hyperactivity/inattention, peer relationship problems and prosocial behaviour). ${ }^{7}$ Each dimension is derived from five items, such as 'Shares readily with other children (treats, toys, etc.)' (Goodman, 1997). For each item, the possible answers are 'not true' (0 points), 'somewhat true' (1), and 'certainly true' (2). The groups of five answers are combined in a total score for each socioemotional dimension, ranging from 0 to 10 . Lower scores identify positive traits for the first four dimensions, while a higher score identifies more positive traits regarding prosocial behaviour. Table 1 summarises the dependent variables for children aged 7 and 11 years old, while the distribution of their outcomes is presented in Fig. 1. ${ }^{8}$

The main independent variables in our analysis are the activities undertaken by children in their free time. The data provides information about an extensive range of activities, including playing a musical instrument, going to the library, attending religious services and classes, participating in sports, reading, watching TV and playing electronic games. In waves 3 and 4 (at ages 5 and 7), we also have information about other activities conducted with the parents: parents reading to the child, playing music with the child and drawing with the child. Unfortunately, the data does not provide the number of minutes/hours spent on each activity, only a measure of frequency (e.g. Every day/Several times a week/Once or twice a week/Once or twice a month/Less often/Not at all). We recode the frequency of most activities as dummy variables where 1 indicates that the activity is conducted at least once a week. The

\footnotetext{
5 In the economic literature, non-cognitive skills encompass several characteristics that have an impact on school and labour market performance not measured by IQ and achievement tests. They include behavioural and socio-emotional development, personality traits, goals, motivation, self-control, locus of control, etc. (Heckman \& Kautz 2013). The five dimensions measured by the SDQ (emotional symptoms, conduct problems, hyperactivity/inattention, peer relationship problems and prosocial behaviour) measure emotional and behavioural aspects, and we alternatively refer to them as behaviour/behavioural dimensions or socio-emotional dimensions.

6 In wave 1 , in 18,515 of the 18,552 families, the respondent to the main questionnaire is the natural mother (for more information about the respondents see also the MCS Guide to the Datasets (Hansen, 2012)).

7 The questions included in the SDQ are shown in Appendix B, alongside a comparison with international normative data (Table 21)

8 Instead, in the analysis, we use standardised values of the five variables.
} 
Table 1 Children's socio-emotional skills (main outcomes)

\begin{tabular}{|c|c|c|c|c|}
\hline & \multicolumn{2}{|c|}{ Age 7 (wave 4) } & \multicolumn{2}{|c|}{ Age 11 (wave 5) } \\
\hline & Mean & $\mathrm{Sd}$ & Mean & $\mathrm{Sd}$ \\
\hline Emotional symptoms & 1.48 & 1.72 & 1.81 & 1.96 \\
\hline Conduct problems & 1.33 & 1.50 & 1.31 & 1.51 \\
\hline Hyperactivity/inattention problems & 3.28 & 2.49 & 3.01 & 2.43 \\
\hline Peer relationship problems & 1.14 & 1.50 & 1.27 & 1.63 \\
\hline Prosocial behaviour & 8.63 & 1.60 & 8.85 & 1.49 \\
\hline Observations & 10,570 & & 9438 & \\
\hline
\end{tabular}

Socio-emotional skills, derived from the Strength and Difficulties Questionnaire. The SDQ is composed of 25 items asking parents about the behavioural attributes of their child; each dimension is derived from five items (Goodman, 1997-see Appendix B for the questionnaire). For each item, e.g. 'shares readily with other children', possible answers are 'not true' (0 points), 'somewhat true' (1), and 'certainly true' (2). The groups of five answers are summed up in a total score for each socio-emotional dimension, ranging from 0 to 10. Lower scores identify positive traits for emotional symptoms, conduct problems, hyperactivity problems, peer relationship problems, while a higher score identifies more positive traits in terms of prosocial behaviour

only exceptions are represented by homework and video-screen activities, where 1 indicates at least one hour per day. All the activities are listed and described in Table 2 . We report activities at ages 7 and 11, ages at which we study their effects on socioemotional skills, but also at age 5, since we will use past activities as further controls (see Section 3). The first three columns of Table 2 (columns 1 to 3) provide an overview of both the activities recorded over time and the more age-specific ones. Among the activities recorded over time, we see an increase in the time devoted to sport (without parents) and computer use. Columns 4 and 5 in the Table report the proportion of children changing their participation in each activity between the different waves: switching from doing the activity in wave $w$ to not doing it in wave $w+1$, or vice versa. ${ }^{9}$

With so many variables of interest, interpreting the results can be quite challenging, especially as some of the reported variables are likely to capture types of activities that are relatively similar to each other. We therefore implement a principal component analysis (PCA) aimed at developing better insight into the number of common latent dimensions that the different activities may share. ${ }^{10}$

Tables 10-12 in the Appendix report the PCA. In wave 3, we obtain four components, while in waves 4 and 5 we obtain seven components. In Table 3, we summarise the grouping of activities in the different components: (1) activities with parents; (2) sports; (3) library and religious activities; (4) video-screen time; (5)

\footnotetext{
${ }^{9}$ For instance, the share of children playing sport with friends at least once per week when they were 7 and not playing at least once per week when they are 11, plus the share of children that were not playing sport with friends at least once per week when they were 7 but playing sports at least once per week when they are 11 , is $12 \%$ of the sample.

${ }^{10}$ We use polychoric correlations to construct the covariance matrix from which the eigenvalues and eigenvectors are calculated. To choose the number of components retained, we apply the Kaiser criterion, selecting a number of components equal to the number of eigenvalues greater than 1 . Finally, to facilitate the interpretation of the extracted components, we rely on orthogonal rotation using the varimax approach.
} 
reading, caring and tidying-up (which covers reading, caring for pets and looking after an elderly household member and tidying up); (6) Extra hours at school (including after school and before school classes); and (7) school-related activities (including homework and extra classes). No components express extra hours at school, school-related activities or reading/caring activities for children when they are 5 years old. Notably, in applying the PCA, similar activities are grouped together, as one would do without statistical methods.

Some activities are clearly related to one particular component, and are always associated with the same component over the three waves, like watching TV or playing with the computer. The same happens for the four activities related to the extra-hours at school and school-related activities. Other activities are highly related with more than one component, such as 'parents play active games'. ${ }^{11}$ Importantly, the activities, which are present both when the child is 7 and when the child is 11 (our main ages of interest), are allocated to the same components in the two waves.

\section{Empirical methods}

Our aim is to estimate the effects of children's time allocation on five socioemotional outcomes. For the main specification, we chose a cumulative value-added (CUVA) model (Section 3.1), whose results are shown for outcomes at ages 7 and 11. To test their robustness to possible endogenous issues, we handled the risk of omitted variables bias in Section 3.2, the risk of reverse causality in Section 3.3 and the risk of measurement error bias due to the inclusion of past values of the dependent variable in Section 3.4. Finally, in Section 3.5, we propose a fixed-effect model (FE), which allowed us to consider unobservable time-invariant characteristics, although it does not permit estimation of age-specific effects.

\subsection{The cumulative value-added model}

With the CUVA specification for each child's socio-emotional skill, we estimated the following linear equation with OLS, once for outcomes at age $t=7$ and once for outcomes at age $t=11$ :

$$
Y_{i, t}=\alpha_{t}+A_{i, t}^{\prime} \beta_{1 t}+A_{i, t-m}^{\prime} \beta_{2 t}+\beta_{3 t} Y_{i, t-m}+Z_{i, t}^{\prime} \beta_{4 t}+\varepsilon_{i, t}
$$

where $Y$ represents one of the five child socio-emotional outcomes for child $i$ at age $t$, vector $A$ indicates the components expressing different uses of time and vector $Z$ indicates the control variables of child $i$ at or before age $t$. The subscript $m$ is equal to 2 when we estimate the effects at age 7, including time-use components and

\footnotetext{
${ }^{11}$ In wave 3, 'parents play active games' has its highest loading in the 'sport' component (0.549), but is also high in the component regarding 'activities done with parents' $(0.526)$; in waves 4 and 5 , it is more related to the latter component. Similarly, the activity 'sport with parents' enters the 'sport' component in wave 3 , and the 'activity with parents' component in wave 4 (although having a quite high loading in the 'sport' component).
} 
Table 2 Activities

$\begin{array}{lllll}\text { Age } 5 & \text { Age } 7 & \text { Age 11 } & \Delta \text { Age } & \Delta \text { Age } \\ \text { (wave 3) } & \text { (wave 4) } & \text { (wave 5) } & \text { 5-age 7 } & \text { 7-age 11 }\end{array}$
(1)
(2)
(3)
(4)
(5)

\begin{tabular}{|c|c|c|c|c|c|}
\hline Parents read to child (1 pw) & $0.95(0.21)$ & $0.90(0.29)$ & & 0.11 & \\
\hline Parents tell story (1 pw) & $0.56(0.50)$ & $0.46(0.50)$ & & 0.33 & \\
\hline Parents play music (1 pw) & $0.87(0.34)$ & $0.77(0.42)$ & & 0.21 & \\
\hline Parents draw (1 pw) & $0.66(0.47)$ & $0.43(0.50)$ & & 0.38 & \\
\hline Parents play indoors (1 pw) & $0.86(0.35)$ & $0.69(0.46)$ & $0.45(0.50)$ & 0.27 & 0.41 \\
\hline Parents talk to child ( $1 \mathrm{pw}$ ) & & & $0.97(0.17)$ & & \\
\hline $\begin{array}{l}\text { Evenings/weekend with } \\
\text { family at home ( } 1 \mathrm{pw})\end{array}$ & $0.96(0.21)$ & $0.97(0.18)$ & & 0.06 & \\
\hline $\begin{array}{l}\text { Parents at the park- } \\
\text { playground ( } 1 \mathrm{pw})\end{array}$ & $0.61(0.49)$ & $0.50(0.50)$ & & 0.35 & \\
\hline $\begin{array}{l}\text { Parents play active } \\
\text { games ( } 1 \mathrm{pw})\end{array}$ & $0.60(0.49)$ & $0.50(0.50)$ & $0.30(0.46)$ & 0.36 & 0.39 \\
\hline $\begin{array}{l}\text { Sport-physical activities with } \\
\text { parents }(1 \mathrm{pw})\end{array}$ & $0.70(0.46)$ & $0.78(0.41)$ & & 0.34 & \\
\hline $\begin{array}{l}\text { Sport-physical activities with } \\
\text { friends }(1 \mathrm{pw})\end{array}$ & & $0.94(0.23)$ & $0.91(0.28)$ & & 0.12 \\
\hline $\begin{array}{l}\text { Sport-physical } \\
\text { activities ( } 1 \mathrm{pw})\end{array}$ & $0.27(0.44)$ & $0.44(0.50)$ & $0.77(0.42)$ & 0.33 & 0.42 \\
\hline Club (1 pw) & & $0.14(0.35)$ & & & \\
\hline Bike (1 pw) & & & $0.50(0.50)$ & & \\
\hline Library (1 pw) & $0.09(0.29)$ & $0.08(0.28)$ & $0.08(0.28)$ & 0.12 & 0.13 \\
\hline Religious activities (1 pw) & $0.19(0.39)$ & $0.21(0.41)$ & $0.20(0.40)$ & 0.13 & 0.13 \\
\hline Watches TV/videos (1 h pd) & $0.79(0.41)$ & $0.80(0.40)$ & $0.83(0.37)$ & 0.24 & 0.23 \\
\hline Uses computer $(1 \mathrm{~h} \mathrm{pd})$ & $0.22(0.42)$ & $0.35(0.48)$ & $0.45(0.50)$ & 0.32 & 0.39 \\
\hline Reads (1 pw) & & $0.83(0.37)$ & & & \\
\hline $\begin{array}{l}\text { Plays a music instrument (1 } \\
\text { pw) }\end{array}$ & & & $0.42(0.49)$ & & \\
\hline $\begin{array}{l}\text { Tidying up and caring for } \\
\text { pets ( } 1 \mathrm{pw})\end{array}$ & & $0.79(0.40)$ & $0.79(0.40)$ & & 0.23 \\
\hline $\begin{array}{l}\text { Looks after elderly family } \\
\text { members ( } 1 \mathrm{pw})\end{array}$ & & & $0.09(0.29)$ & & \\
\hline Homework (1 h pd) & & $0.64(0.48)$ & $0.85(0.36)$ & & 0.36 \\
\hline Extra classes (1 pw) & & $0.05(0.21)$ & $0.19(0.40)$ & & 0.19 \\
\hline After school class ( $1 \mathrm{pw})$ & & $0.21(0.41)$ & $0.30(0.46)$ & & 0.34 \\
\hline Before school class (1 pw) & & $0.12(0.33)$ & $0.14(0.35)$ & & 0.16 \\
\hline Observations & 10,570 & 10,570 & 9438 & & \\
\hline
\end{tabular}

In the first three columns, we report the proportion of children doing certain activities; ' 1 pw' stands for 'at least once per week'; ' $1 \mathrm{~h}$ pd' stands for 'at least one hour per day'. Standard deviations in parentheses. In the last two columns, we report the proportion of children changing the participation into the single activities between the different waves, i.e. from not doing an activity to doing it, or vice versa 
Table 3 Principal component analysis for activities in the three waves

\begin{tabular}{|c|c|c|c|}
\hline Variables & Age 5 (wave 3) & Age7 (wave 4) & Age 11 (wave 5) \\
\hline Parents read to child ( $1 \mathrm{pw}$ ) & $\mathrm{C} 1$ & $\mathrm{C} 7$ & \\
\hline Parents tell story $(1 \mathrm{pw})$ & $\mathrm{C} 1$ & $\mathrm{C} 1$ & \\
\hline Parents play music $(1 \mathrm{pw})$ & $\mathrm{C} 1$ & $\mathrm{C} 1$ & \\
\hline Parents draw $(1 \mathrm{pw})$ & $\mathrm{C} 1$ & $\mathrm{C} 1$ & \\
\hline Parents play indoors ( $1 \mathrm{pw})$ & $\mathrm{C} 1$ & $\mathrm{C} 1$ & $\mathrm{C} 1$ \\
\hline Parents talk to child ( $1 \mathrm{pw})$ & & & $\mathrm{C} 1$ \\
\hline Evenings or weekend with family at home (1 pw) & $\mathrm{C} 1$ & $\mathrm{C} 1$ & \\
\hline Parents at the park-playground (1 pw) & $\mathrm{C} 2$ & $\mathrm{C} 1$ & \\
\hline Parents play active games ( $1 \mathrm{pw})$ & $\mathrm{C} 2$ & $\mathrm{C} 1$ & $\mathrm{C} 1$ \\
\hline Sport with parents $(1 \mathrm{pw})$ & $\mathrm{C} 2$ & $\mathrm{C} 1$ & \\
\hline Sport with friends (1 pw) & & $\mathrm{C} 2$ & $\mathrm{C} 2$ \\
\hline Sport activities $(1 \mathrm{pw})$ & $\mathrm{C} 2$ & $\mathrm{C} 2$ & $\mathrm{C} 2$ \\
\hline Club $(1 \mathrm{pw})$ & & $\mathrm{C} 2$ & \\
\hline Bike $(1 \mathrm{pw})$ & & & $\mathrm{C} 2$ \\
\hline Library (1 pw) & C3 & $\mathrm{C} 3$ & $\mathrm{C} 3$ \\
\hline Religious activities ( $1 \mathrm{pw})$ & $\mathrm{C} 3$ & $\mathrm{C} 3$ & $\mathrm{C} 3$ \\
\hline Watches TV/videos $(1 \mathrm{~h} \mathrm{pd})$ & $\mathrm{C} 4$ & $\mathrm{C} 4$ & $\mathrm{C} 4$ \\
\hline Uses computer $(1 \mathrm{~h} \mathrm{pd})$ & $\mathrm{C} 4$ & $\mathrm{C} 4$ & $\mathrm{C} 4$ \\
\hline Reads $(1 \mathrm{pw})$ & & $\mathrm{C} 5$ & \\
\hline Plays a music instrument (1 pw) & & & C4 (neg) \\
\hline Tidying up and caring for pets ( $1 \mathrm{pw})$ & & $\mathrm{C} 5$ & $\mathrm{C} 5$ \\
\hline Looks after elderly family members ( $1 \mathrm{pw})$ & & & $\mathrm{C} 5$ \\
\hline Homework (1 h pd) & & $\mathrm{C} 7$ & $\mathrm{C} 7$ \\
\hline Extra classes $(1 \mathrm{pw})$ & & $\mathrm{C} 7$ & $\mathrm{C} 7$ \\
\hline After school class $(1 \mathrm{pw})$ & & C6 & C6 \\
\hline Before school class (1 pw) & & C6 & C6 \\
\hline
\end{tabular}

\section{Components}

$\mathrm{C} 1$ : activities with parents

C2: sports

C3: library and religious activities

C4: video-screen time

C5: reading and caring/tidying up

C6: extra hours at school

C7: school-related activities

C1-C7 identify to which component the variable is most correlated with. The correlations between the activities (first columns) and the extracted components are all positive, except for music, which is negatively correlated with the component 'video-screen time' in wave 5. Grey cells correspond to activities that are not present in that wave. ' $1 \mathrm{pw}$ ' stands for 'at least once per week'; ' $1 \mathrm{~h}$ pd' stands for 'at least $1 \mathrm{~h}$ per day' 


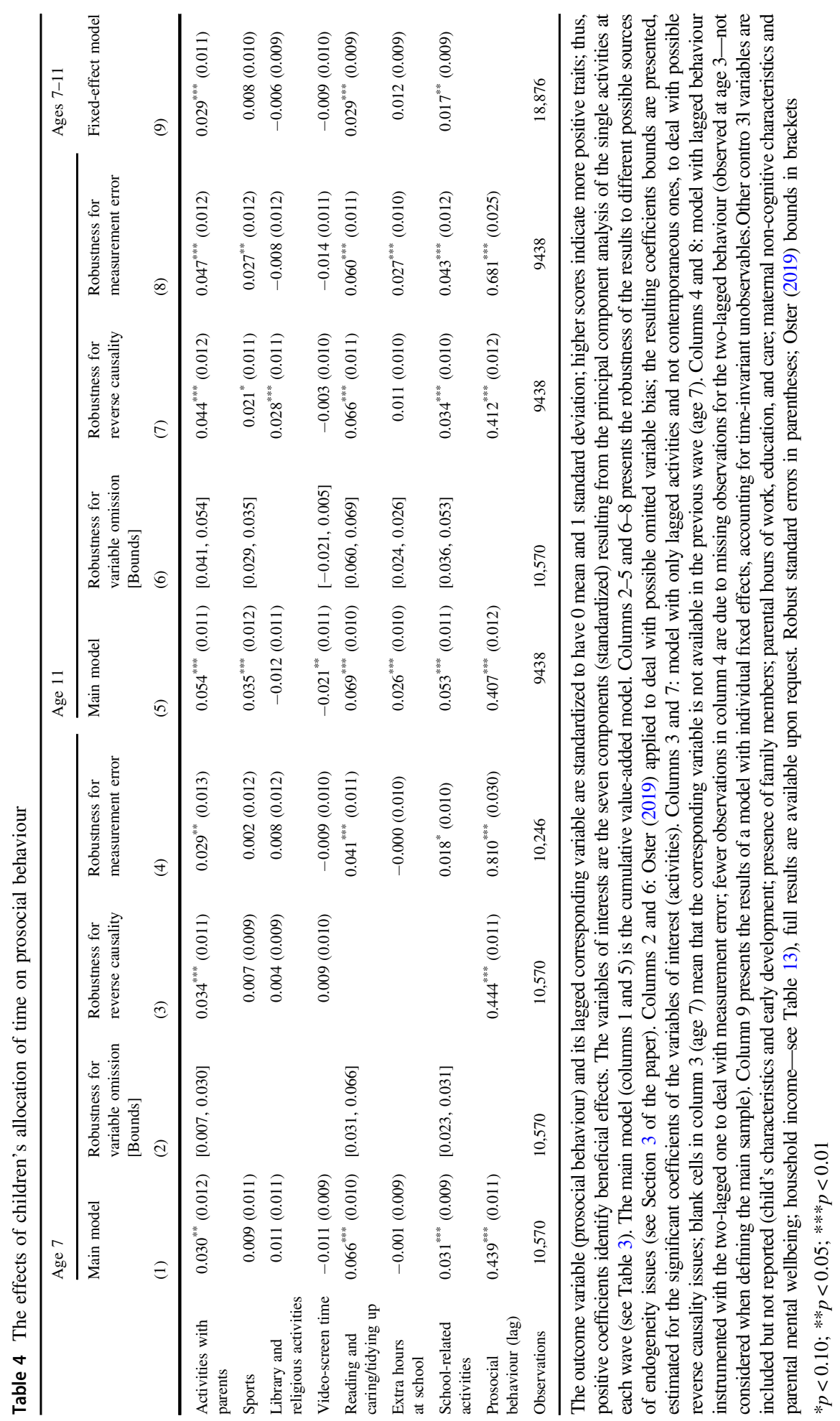




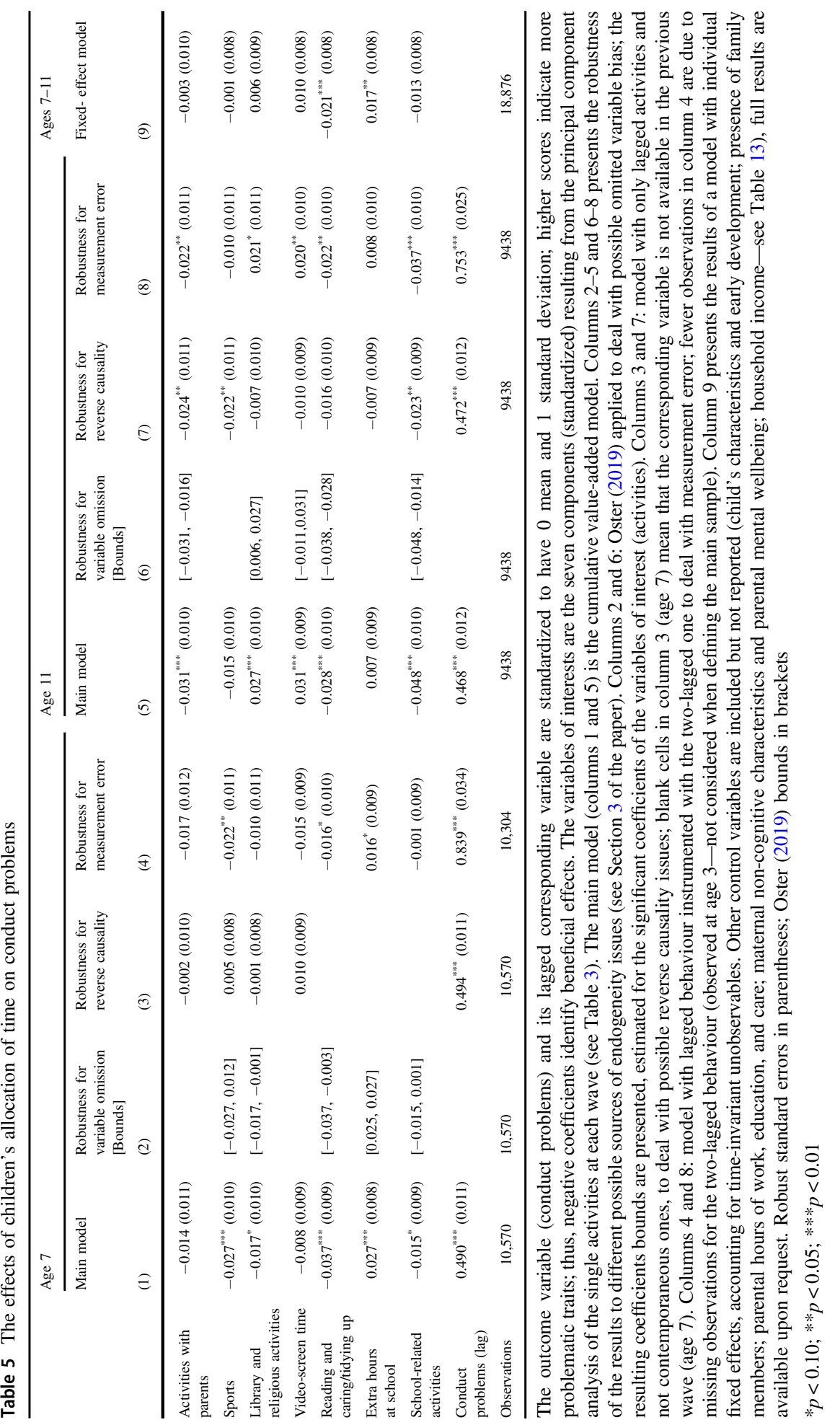




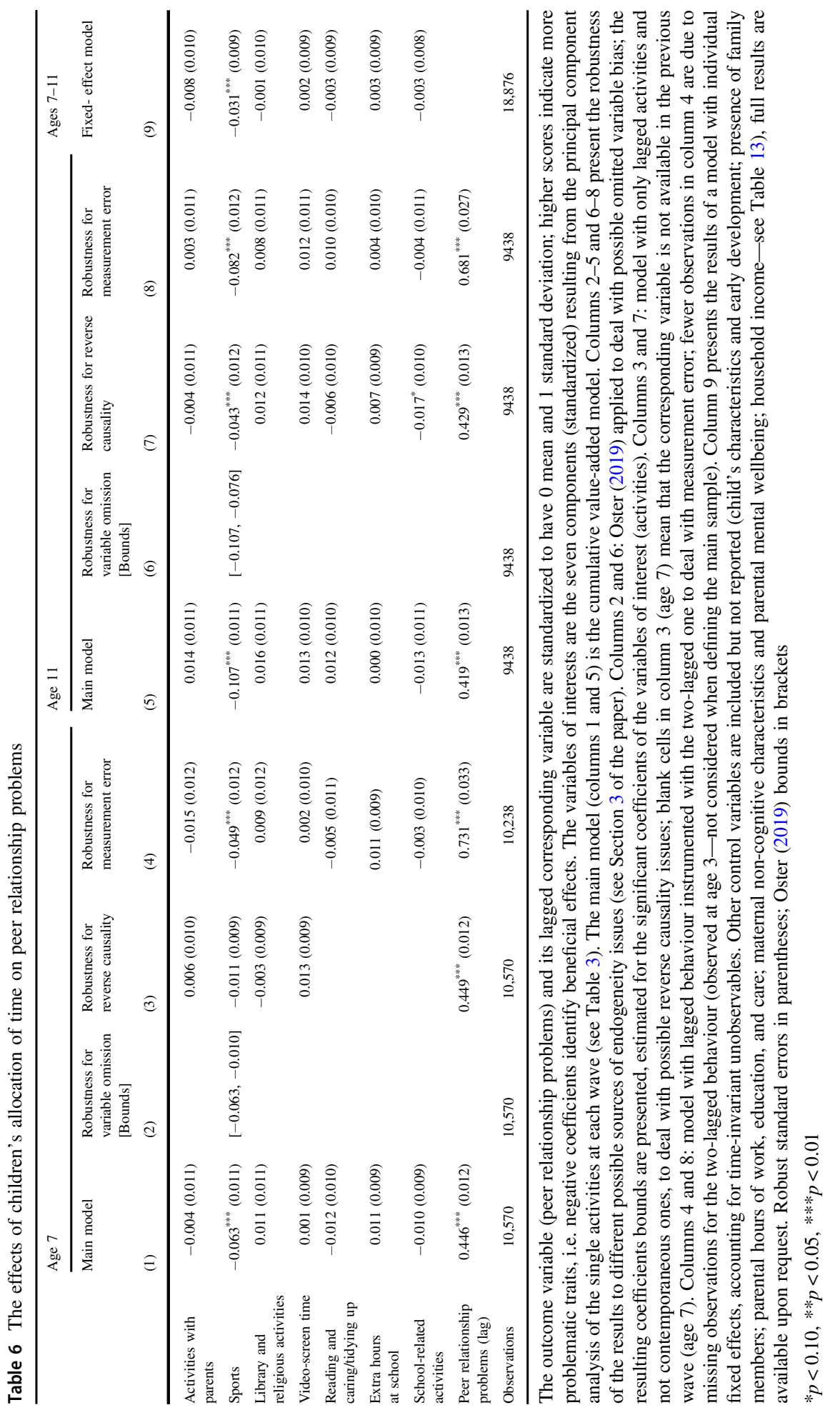




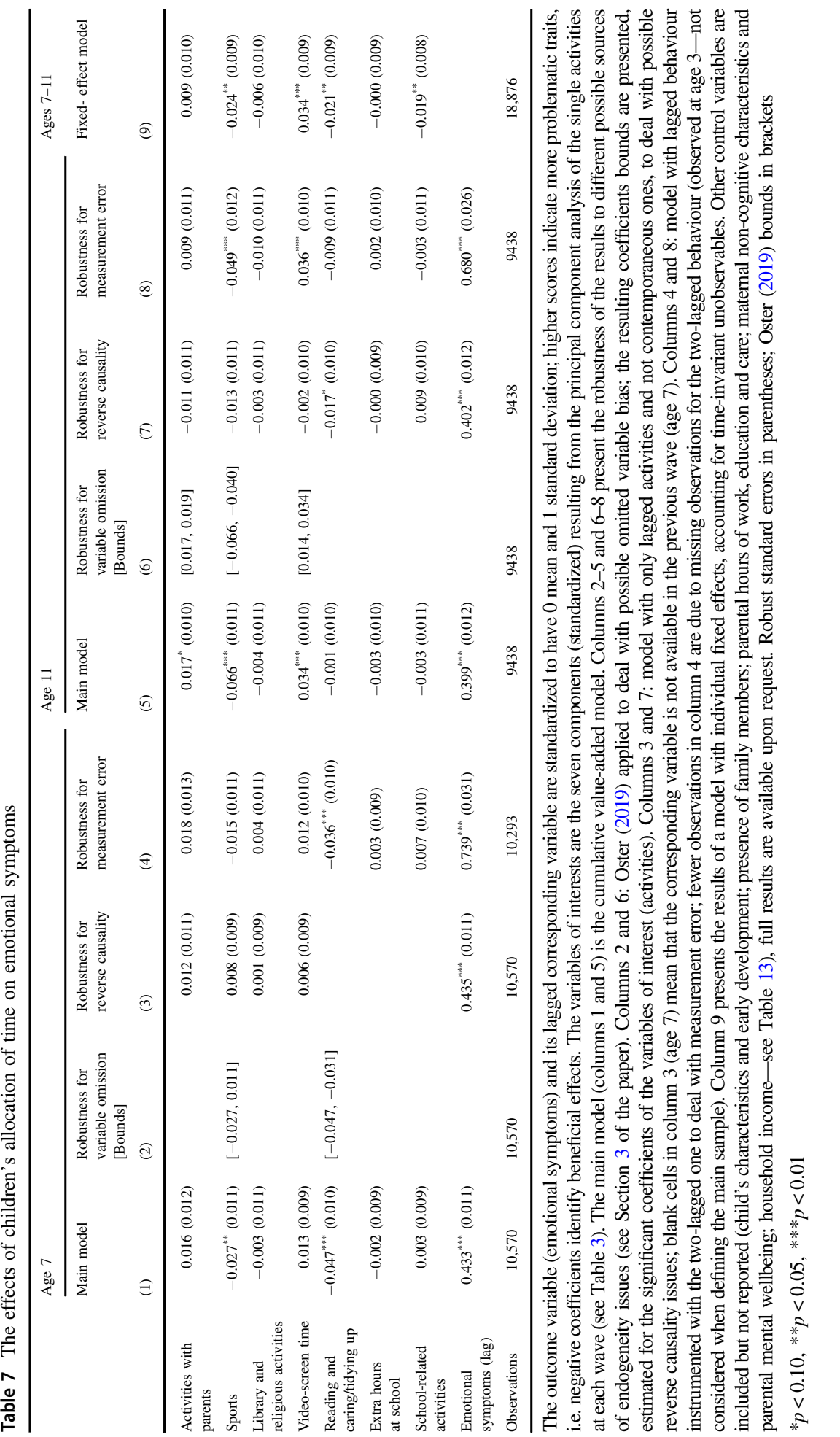




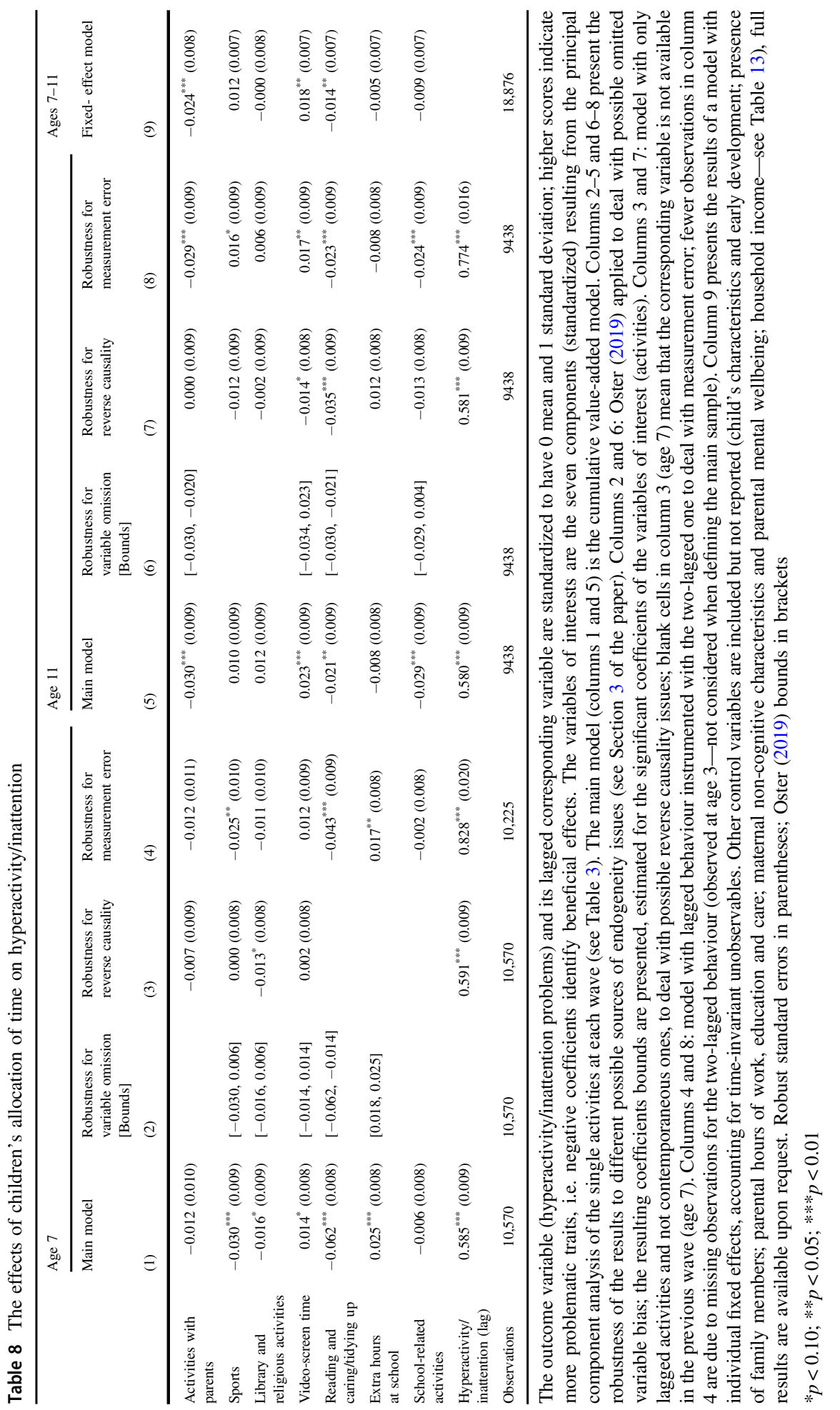


outcomes measured at age 5 , and is equal to 4 when we estimate the effects at age 11 , including time-use components and outcomes measured at age $7 .{ }^{12} \beta_{1}$ is the coefficient of interest. In this model, we included information regarding the past use of the child's time (allowing for a 'lagged' effect) and information on the child's noncognitive outcome in the previous wave, which can control for most of the differences across children. ${ }^{13}$ The inclusion of past values of the output in the model should capture all unobservable past inputs and unobservable characteristics of the child, e.g. her/his temperament, talents and preferences. This model is equivalent to comparing the socio-emotional skills of two children at age 7 (11) who used to have the same skill indicator and time inputs at age 5 (7), but may have used their time in a different way between ages 5 and 7 (7 and 11).

The assumptions underlying model (1) include the following: the information contained in vector $Z$ and $Y_{i, t-m}$ is a good proxy of any unobserved inputs and unobservable characteristics of the child; the effect of unobserved inputs and child's characteristics declines with age at the rate $\beta_{3}$; and there is no remaining unobserved heterogeneity that correlates with activities at age $t$ (Todd \& Wolpin, 2003, 2007; for details about these assumptions).

Examples of variables contained in vector $\mathrm{Z}$ are personal characteristics, parents' and family characteristics and socio-economic circumstances. The detailed descriptive statistics are reported in Table 13 (panel A to C). First, we considered variables that describe the environment/context that children are faced with, referred to as environmental variables (Table 13, panel A). They were measured in the same waves as the main outcomes (at ages 7 and 11) and are related to the household dimension (mother, father, siblings and grandparents' presence in the household; parental hours of work). A second set of variables account for previous parental investments (before age 7), and are fixed over time (Table 13, panel B): whether the child was breastfed, how long the mother stayed at home after birth, type of childcare when the child was 30 months old, father's involvement with the child when the child was 9 months old and parental education. Third, we included some socio-demographic control variables concerning the child, parents and household (Table 13, panel C) that may correlate with the use of time and may affect the outcomes. Control variables about the child were all measured in the first wave: gender, nationality, birth weight, age, number of siblings at birth, hospitalisations, accidents and the three indicators of child development in the first year of life, ${ }^{14}$ which capture child

\footnotetext{
12 We are aware that a 2-year lagged variable might capture more than a 4-year lagged variable, but given the timing of the survey, this is the best that can be done. Results from the contemporaneous models (Tables 16-20) can give insights on this point.

13 For the estimation of the effects of interest we follow Todd \& Wolpin (2003, 2007) and Fiorini \& Keane (2014). Instead of the CUVA specification, one could use contemporaneous inputs only, contemporaneous and lagged inputs (cumulative model-CU) or contemporaneous inputs and lagged output (value-added model-VA). See Todd \& Wolpin (2003) for a discussion of the different assumptions underlying each model. Particularly, the inclusion of the lagged dependent variable in the VA and CUVA specifications may induce endogeneity problems. We present results from these specifications as robustness checks in Section 4.2. However, as most of the results are confirmed using the different models, we decided to focus on the CUVA specification, which is the most restrictive one, and whose results are always confirmed in other models.
}

14 The three indicators of child development in the first year of life refer to the communication, motor, and motion dimensions. They are derived-through PCA — from information in wave 1 (see Table 14 in the Appendix). 
endowments at an early age and are known to be predictive of later development (Hernández-Alava \& Popli, 2017). We included the following variables concerning the parents: quality of the child-mother relationship, ${ }^{15}$ locus of control of the mother, ${ }^{16}$ mother's personality type ${ }^{17}$ and parents' mental wellbeing. ${ }^{18,19}$ Regarding the household, we included the presence of new-borns, household equivalent income (both measured at the current wave), household location (England, Scotland, Wales and Northern Ireland) and whether the child had been on holidays outside the UK in the past year.

Finally, in addition to the child's development at nine months, to consider the correlation between the different abilities of the child as s/he grows older, we included one variable measuring the child's cognitive ability during the previous wave, which was derived through PCA of the cognitive items available in the survey (see Table 15 in the Appendix). ${ }^{20}$ At age 7, we considered past measures of abilities in naming objects, coordinating figures in the spatial dimension and problem-solving (measured at age 5). For age 11, we considered past measures of abilities in reading, math and coordinating figures in the spatial dimension (measured at age 7).

Although we can control for a large set of variables using the CUVA specification, causal interpretation of the results remains tentative, as discussed and addressed hereafter.

\subsection{Risk of variable omission}

Although the model included the lag of the dependent variable and a large set of control variables, there may still be unobservable characteristics of the child/family that correlate with time use and child behaviours. For example, a young boy might be very shy and therefore be both less likely to engage in sports and more likely to be bullied by schoolmates, without less sport directly causing more peer problems. Or, strict parents may require the child to tidy up the room and also directly affect the child's level of obedience.

We handled the risk of omitted variable bias by applying a method designed to assess the stability of coefficients in the presence of unobservable selection (Oster, 2019) to the CUVA specification. This method, building on the previous study by Altonji et al. (2005), evaluated the robustness of results against omitted variable bias, assuming that the relationship between the treatment and the unobservables can be recovered from the relationship between the treatment and the observables and allowed the coefficient of interest to be bound in the presence of such omitted variable bias. Consequently, we need

\footnotetext{
15 Two variables are included (measured in wave 2) that regard child-mother closeness and conflicts (see the MCS Guide to the Psychological, Developmental and Health Inventories (Johnson et al., 2015, page 56)).

16 Measured in wave 1. It is a dummy variable on the mother's locus of control that corresponds to her statement 'I usually have a free choice and control over my life'.

17 The two variables are measured in wave 4 and regard the mother being extroverted and neurotic (see Johnson et al., 2015, page 63).

18 Measured with the Kessler K6 Scale in each wave (see Johnson et al., 2015, pages 57-61).

19 For robustness, we also estimate the models without the independent variables explained in notes 13-16. Results are similar in size and significance and are available upon request.

20 As mentioned earlier, no cognitive indicator is repeated over the three waves, and between waves 4 and 5. Nevertheless, the PCA suggests that the cognitive indicators capture a unique component, which can be considered a latent cognitive skill.
} 
to choose a level of $R_{\max }$ that corresponds with the R-squared from a hypothetical regression of the outcome on the treatment and both the observed and unobserved controls. If the outcome could be fully explained by the treatment and full control set, then $R_{\max }$ would be 1 ; however, in many empirical settings, it seems likely that the outcome cannot be fully explained, even if the full control set is included (e.g. due to measurement error). Therefore, one needs to choose a bound of $R_{\max }$, and Oster (2019) proposed focusing on bounds that are a function of the observed R-squared of the regression with a full set of observable controls. We chose $R_{\max }=1.3 \mathrm{R}$-squared, as suggested by Oster (2019). We subsequently calculated the bounds of the estimated coefficients for different values of the relative degree of the selection on the observed and unobserved variables $(\delta)$. We focused on $\delta=0$, corresponding with the original estimates, and $\delta=1$ as the upper bound, which corresponds with the assumption of equal selection between observed and unobserved variables, as suggested by Oster (2019).

\subsection{Risk of reverse causality}

Regarding reverse causality, all the estimates control for past socio-emotional problems, so this issue was already partially solved. However, it is still possible that even under the same value of socio-emotional skills at age 7 , reverse causality emerges in the relationship between socio-emotional skills and activities at age 11. Thus, to test our results against the risk of reverse causality, we decided to include only the value of past engagement in the different activities on current socio-emotional skills in the regressions.

\subsection{Risk of measurement errors}

The estimated model, which includes lagged values of the dependent variables, implicitly considers omitted past inputs and controls for unobservable characteristics of the child, e.g. her/his temperament, talents and preferences. However, there could be a problem if past outcomes are measured with error, as this can induce biased estimates. Therefore, to address measurement error in the lagged outcomes, we used the instrumental variable method: using a two-period lagged outcome as an instrument for the one-period lagged outcome is an acknowledged solution to measurement error in value-added models (Arellano \& Bond, 1991; Andrabi et al., 2011; Del Bono et al., 2016).

\subsection{Fixed-effect model}

To consider the unobservable characteristics fixed over time, an alternative strategy is to estimate the model with individual fixed effects (FE). The FE specification is useful when we want to relax the assumption about no unobserved heterogeneity that correlates with extra school activities at age $t$. For this specification, using data from both waves, we estimated the following equation:

$$
Y_{i, t}=\alpha_{t}+A_{i, t}^{\prime} \beta_{t}+Z_{i, t}^{\prime} \theta_{t} v_{i}+e_{i, t}
$$

With this model, including child fixed-effects $v_{i}$, we can observe whether a change in the frequency of activities conducted between ages 7 and 11 explains part of the difference in the child's socio-emotional skills over time, eliminating the effect of the unobservable characteristics fixed over time as well as other unobserved family 
characteristics fixed over time. In this model, vector $Z$ includes only time-varying covariates, i.e. only the controls presented in panel A of Table 15 and the time-varying controls in panel $\mathrm{C}$ : the presence of new-borns, household equivalent income, holidays outside the UK in the past year and the child's cognitive ability at the previous wave.

CUVA and child FE specifications rely on different assumptions about the relationship between the child's time use and outcomes. In the first case, the model allowed for a temporal adjustment because the present effect of an activity can be different from the effect of the same activity in the past. With the child FE, we assumed instead that the input effects are age invariant.

\section{The effects of time allocation}

\subsection{Main results}

The effects of time use-represented as different components-on the five socioemotional skills are presented in Tables 4-8. For each outcome, and separately at ages 7-11, the tables report the effects of the activities obtained with the CUVA specification (columns 1 and 5), the Oster bounds (columns 2 and 6), the effects of the lagged activities (columns 3 and 7) and the effects of the activities when dealing with the endogeneity of the lagged dependent variable (columns 4 and 8). The last column reports the effects estimated when employing FE and the whole sample. A negative sign of the coefficient indicates that the activity reduces that behavioural problem and thus has a 'beneficial' effect, or vice versa. The only exception is the prosocial dimension, which must be read backwards (a negative sign of the coefficient indicates a detrimental effect). When reading the effects of the lagged activities, we need to remember that some activities are not observed at age 5, and therefore, their effect at age 7 cannot be estimated (column 3).

Overall, we find that time spent with parents and time on sports, school-related activities, reading and caring/tidying up have beneficial effects, while extra hours at school and video-screen time have harmful effects. No effects were found for participating in religious activities or going to the library. Prosocial behaviour, which improves children's ability to share with others and be helpful, proves to be the dimension most responsive to time allocation. All non-cognitive dimensions are strongly correlated over time.

We now comment on the strongest results, namely, those found in our main specification and robust against endogeneity issues. It may happen that they are not confirmed (models to test against omitted variable bias, reverse causality, or measurement error are more restrictive): if that is the case, such results are not presented in this discussion. Both the dependent and independent variables are standardised, which makes it easier to read the results.

Prosocial behaviour is influenced positively by several activities (Table 4): time spent with parents, reading and caring/tidying up, conducting school-related activities at both ages and doing sports at the age of 11 .

Conduct problems are reduced at both ages by reading and caring/tidying up (also confirmed by the FE model) and at age 11 by time spent with parents and on schoolrelated activities (Table 5). Peer problems are reduced at both ages by sports activities, as also confirmed by the FE (Table 6). Emotional symptoms were mitigated at age 7 by 
reading and caring/tidying up and at age 11 by sport activities (Table 7). However, screen time has a detrimental effect on a child's emotional sphere at age 11.

Both reading and caring/tidying up decreased inattention problems at both ages, as also confirmed by the FE model. Children aged 11 who spend more active time with their parents present fewer hyperactivity/inattention problems (Table 8). Instead, spending more time at school at younger ages increases this type of problem.

Overall, time spent with parents reading, playing games has a beneficial effect on prosocial behaviour, conduct and inattention problems. Reading and caring/tidying up positively influence prosocial behaviour and decrease inattention, conduct and emotional problems. Time spent on homework and extracurricular activities at school improves prosocial behaviour and reduces conduct problems. Sport has beneficial effects on prosocial behaviour, peer problems and emotional symptoms. In contrast, video-screen time has a detrimental effect on the emotional sphere of older children, and extra time spent at school may increase hyperactivity issues in younger children.

In terms of size, the estimated effects indicate that one standard deviation (s.d.) of difference in activities leads to 0.03-0.11 s.d. in difference in behavioural dimensions. By means of comparison, studies documenting the impacts of ad hoc interventions targeting socio-emotional skills find effects of $0.15-0.30$ s.d., depending on the program, the outcome, and the time elapsed between the intervention and observed outcome. ${ }^{21}$ Compared to these findings, results for the allocation of time appear relatively small, but one needs to keep in mind that this is 'standard' use of time and not an ad hoc program. Instead, the magnitude is comparable to estimates presented in studies on the effect of time use on cognitive skills. For instance, according to Fiorini \& Keane (2014) an additional hour of educational activities with parents improves cognitive skills by 0.02-0.04 s.d., and according to Del Bono et al. (2016) educational time with the mother improve verbal skills by $0.04-0.05$ s.d. at age 7 (contemporaneous and CUVA models respectively).

To better understand the effect sizes in our setting, we make some predictions. We need to remind that the dependent variable is the sum of the mother's answers, which can take the value 0,1 , or 2 ; lower scores identify positive traits for the first four socio-emotional dimensions, whereas higher scores identify positive traits regarding prosocial behaviour (see Section 2 for the details). Compare, for example, an 11year-old child who does sports and goes biking at least once a week with a child with the same characteristics but who does not perform these activities or does them less often. The mother of the first child will provide fewer (negative) answers when asked about the child's emotional sphere, inducing a reduction in the average emotional symptom score of 0.51 (from 2.19 to 1.68 score); she will also give fewer negative answers when asked about peer problems, yielding an average reduction of 0.80

\footnotetext{
${ }^{21}$ In a meta-analysis, Durlak et al. (2011) document the effects of school-based programs expressly designed to improve students' social and emotional development; they find a short-term mean effect of 0.30 s.d. and a medium-term effect after one year (median period) of 0.26 s.d. Algan et al. (2014) show that an intervention focused on non-cognitive skills at age 7 for implies an improvement in term of aggression control, attention-impulse control, and trust of 0.15-0.19 s.d. More recently, Sorrenti et al. (2020) find effects of about 0.15 s.d. for children participating in an ad hoc intervention targeting socio-emotional skills, with a reduction of ADHD symptoms (disruptiveness and impulsiveness) and opposition and defiance, and an improvement in non-aggressive conduct behaviour; these effects are measured one to three years after the intervention. Kosse et al. (2020) detect an improvement by 0.27 s.d. in prosociality (short-term) for primary school children who were offered a 1-year mentoring intervention.
} 
(from 1.87 to 1.07). Instead, she will answer positively more often when asked about prosocial behaviour, yielding an increase of 0.23 points (from 8.68 to 8.91 ). Conversely, the mother of a child who both watches TV and uses a PC more than an hour per day will answer more often that her child has emotional problems, with an increase of 0.10 (from 1.73 to 1.83 ) in the score. ${ }^{22,23}$

We also investigated the possible heterogeneous effects of time use according to socio-economic status, ethnic background, gender, and family composition, but we found no strong evidence for any heterogeneous effect. ${ }^{24}$ However, if children from different context have different likelihood of spending time on the activities, the overall benefits may be unequally distributed across them. The findings, available as online supplemental material, show that children from more advantaged backgrounds are more exposed to enriching uses of their time and less exposed to detrimental ones. Consequently, differences in the use of time by children from different family backgrounds should be considered as an additional source of inequality.

Most of the beneficial effects we find on the child's socio-emotional skills follow previous findings on the cognitive dimensions of children. In addition to the positive influence of participating in sports and activities with parents on many educational outcomes found in previous studies, here we also find positive effects on noncognitive outcomes. New evidence is then provided for the beneficial effects of time spent on activities performed at home, such as reading, doing homework and caring for pets and other people.

Our results seem to differ from those of Fiorini \& Keane (2014) and Del Bono et al. (2016), since neither of those studies found effects on non-cognitive outcomes. Differences with results in Fiorini \& Keane (2014) may be due to institutional differences across the two countries, different sample sizes, the age-range considered and different econometric specifications. On the other hand, while the use of the same data and the same econometric specification in Del Bono et al. (2016) question the causes of different results, there are two major differences which motivate them: the inclusion of prosocial behaviour as an outcome-which is not included in their estimates and turns out to be very responsive to time allocation-and the analysis of different categories of time use, not only time with parents. For the major overlap between the two studies (parental time at age 7), we find that time spent with parents has a positive effect only on prosocial behaviour. ${ }^{25}$

The results follow psychological studies on child non-cognitive development, which underline the beneficial effects of active and dynamic uses of time versus the

\footnotetext{
22 At age 11, Emotional symptoms have an average score of 1.81; Conduct problems 1.31; Hyperactivity 3.01; Peer problems 1.27; Prosocial behaviour 8.85 (Table 10).

${ }^{23}$ We predict the scores in prosocial behaviour, for example, for two children. They have the same average characteristics and activities' frequency as other children in the sample, apart from the principal component related to sport activities: the first child has a larger value since s/he does sport with friends or by him/herself at least once per week and bikes at least once per week. The second child has a lower value since s/he does not conduct these activities or conducts them but less frequently (see factor loading in Table 12 for this specific example).

24 Results available from the authors upon request.

25 We further investigate differences between our results and Del Bono et al. (2016), by replicating the analysis with their specifications. Results are coherent with findings reported here, and are available upon request.
} 
detrimental effects of passive activities. Sports, active time with parents and doing things at home are better than spending time watching TV or using PC and tablets. While dynamic uses of time imply effort and perseverance and therefore provide feelings of satisfaction for the child, this is not true for inactive uses of time (Veenhoven, 1984; Emmons, 2003). Another interesting finding is the substantial influence of several activities on the child's prosocial behaviour, which can be considered a sort of feeling of empathy towards others. This is an attitude expected to grow with the individual, a non-cognitive dimension that measures the passage from 'childhood' (when behaviours are motivated by the need for attachment) to 'adulthood' (when behaviours are motivated by the feeling of looking after someone else) (Solomon \& George, 1996; Nuttall et al., 2015). It is plausible that this ability can be learnt by spending time with parents and other caring adults and observing them. In fact, we find positive effects of time spent with parents, time spent on doing homework (which may also be time shared with parents), taking extra classes (with a tutor) and spending active time within the household (which may also be time shared with other family members) on children's empathy. We also found that sports have a beneficial effect on prosocial behaviour and peer problems; this effect may be due to another mechanism: the need for collaboration (Lichtenberg et al., 2012). In fact, to succeed, the child needs to interact proficiently with his/her companions.

\subsection{Robustness checks}

As mentioned above, instead of including lagged inputs and outputs as control variables, as is done in the CUVA model, one could use contemporaneous inputs only, contemporaneous and lagged inputs (cumulative model-CU), or contemporaneous inputs and lagged output (value-added model-VA).

Tables 16-20 in the Appendix present the results of these different models: (i) the simple OLS model, which estimates the contemporaneous effect of activities on the outcome (Contemp.); (ii) the VA; (iii) the CU and (iv) the CUVA, the main specification of the study. Most of the results are confirmed in the different models; most importantly, all the results in the CUVA model are also present in the other specifications, with the CUVA specification showing the smallest coefficient (with only three exceptions over 70 estimated parameters) confirming CUVA to be the most restrictive model and providing the most conservative estimates among these models. The results discussed in the previous section, which are robust to the different endogeneity issues, are always confirmed.

\section{Conclusion}

In this study, we investigated the relationship between time allocation and children's social, emotional and behavioural skills using UK longitudinal data and testing the robustness of our results to different endogeneity issues. We found that different activities influence the child's non-cognitive development. Overall, sports, schoolrelated activities, reading and caring/tidying up activities and time spent with parents tend to reduce socio-emotional problems, whereas video-screen time had detrimental effects for older children and extra hours at school were harmful for younger ones. 
No effects were found for participating in religious activities or going to the library. The largest positive effect of time use was observed in prosocial behaviour in the form of sharing with others and being helpful. Most of the beneficial effects we found on the child's socio-emotional skills confirm previous findings on her/his cognitive development. To our knowledge, however, this is the first study to find beneficial effects of a child's time allocation on non-cognitive development.

Considering that children from different family backgrounds do not afford the same opportunities for their time use, from a policy perspective our results call for the provision of free to low-cost extra-curricular activities to be held after school, in particular sports and school-related activities. After-school programmes may also reduce time spent on TV and screen time. Additionally, this could be complemented by providing more information to the parents about the beneficial effects of such activities.

There are three main limitations to this study. First, we do not know how much time the child actually spends on any of the activities. Not only would this be another important source of heterogeneity across children, but it could also reveal the nonlinear effects of these activities. Second, to better interpret the results obtained for children's non-cognitive development, it would be useful to know more details about the activities conducted. For example, to understand the level of passivity involved in activities under the video-screen category, we would need to know whether children are watching a movie/cartoon or an interactive cartoon, playing video-games, watching other people playing those video-games, singing or dancing while watching music videos or searching for commercial videos online (e.g. the unboxing of toys). Finally, we do not have a full description of time use. Therefore, we lack information about other important ways children spend their time, such as 'pure' playtime (playing by themselves or with siblings/cousins), time spent at dinner or social events, sleeping routines and the management of boredom and waiting-time. Future studies should investigate such factors to completely unveil the relationship between children's time use and their non-cognitive development.

Acknowledgements We would like to thank the participants in several conferences and seminars. This research was supported by the Progetto d'Ateneo 2014 CHILD-EXTRA-SCHOOL, Università di Torino \& Compagnia di San Paolo. Previous versions of the paper have circulated under the titles 'Use of extra-school time and child behaviour' (FBK-IRVAPP WP 2019-02) and 'Use of ExtraSchool Time and Child Behaviours: Evidence from the UK' (IZA DP 11606). Opinions expressed herein are those of the authors only. Neither the European Commission nor any person acting on behalf of the Commission is responsible for the use that might be made of this publication.

\section{Compliance with ethical standards}

Conflict of interest The authors declare no competing interests.

Publisher's note Springer Nature remains neutral with regard to jurisdictional claims in published maps and institutional affiliations.

Open Access This article is licensed under a Creative Commons Attribution 4.0 International License, which permits use, sharing, adaptation, distribution and reproduction in any medium or format, as long as you give appropriate credit to the original author(s) and the source, provide a link to the Creative Commons license, and indicate if changes were made. The images or other third party material in this article are included in the article's Creative Commons license, unless indicated otherwise in a credit line to the material. If material is not included in the article's Creative 
Commons license and your intended use is not permitted by statutory regulation or exceeds the permitted use, you will need to obtain permission directly from the copyright holder. To view a copy of this license, visit http://creativecommons.org/licenses/by/4.0/.

\section{Appendix A: Additional tables}

Table 9 Sample selection, selected variables

\begin{tabular}{|c|c|c|c|c|c|c|}
\hline \multirow[t]{2}{*}{ Variable } & \multicolumn{2}{|c|}{9 months old (wave 1) } & \multicolumn{2}{|c|}{7 years old (wave 4 ) } & \multicolumn{2}{|c|}{11 years old (wave 5 ) } \\
\hline & Mean & SD & Mean & SD & Mean & SD \\
\hline Mother highly educated & 0.33 & 0.47 & 0.39 & 0.49 & 0.40 & 0.49 \\
\hline $\begin{array}{l}\text { Father highly educated (if } \\
\text { present in the } \mathrm{HH} \text { ) }\end{array}$ & 0.36 & 0.48 & 0.39 & 0.49 & 0.40 & 0.49 \\
\hline $\begin{array}{l}\text { Mother back to work within } \\
6 \text { months of birth }\end{array}$ & 0.35 & 0.48 & 0.38 & 0.49 & 0.39 & 0.49 \\
\hline British & 0.81 & 0.39 & 0.85 & 0.36 & 0.85 & 0.36 \\
\hline Girl & 0.49 & 0.50 & 0.49 & 0.50 & 0.50 & 0.50 \\
\hline Birthweight & 3.36 & 0.58 & 3.38 & 0.57 & 3.38 & 0.58 \\
\hline England & 0.62 & 0.48 & 0.63 & 0.48 & 0.63 & 0.48 \\
\hline Wales & 0.15 & 0.36 & 0.15 & 0.36 & 0.15 & 0.36 \\
\hline Scotland & 0.13 & 0.33 & 0.12 & 0.32 & 0.12 & 0.32 \\
\hline Northern Ireland & 0.10 & 0.30 & 0.10 & 0.30 & 0.10 & 0.30 \\
\hline
\end{tabular}

Means and standard deviation of selected variables in the initial sample (wave 1) and in the analysed samples (wave 4, wave 5). HH stands for household

Table 10 Factor loading of the principal component analysis on activities at age 5 of the child (wave 3)

\begin{tabular}{lcrrrr}
\hline Activities & $\begin{array}{l}\text { Activities with } \\
\text { parents }\end{array}$ & Sports & $\begin{array}{l}\text { Library/religious } \\
\text { activities }\end{array}$ & $\begin{array}{l}\text { Video- } \\
\text { screen time }\end{array}$ & Uniq. \\
\hline Parents read to child (1 pw) & $\mathbf{0 . 5 8 5}$ & 0.278 & 0.097 & -0.171 & 0.542 \\
Parents tell story (1 pw) & $\mathbf{0 . 5 9 9}$ & 0.038 & 0.329 & 0.056 & 0.529 \\
Parents play music (1 pw) & $\mathbf{0 . 7 0 9}$ & 0.093 & -0.043 & -0.050 & 0.485 \\
Parents draw (1 pw) & $\mathbf{0 . 7 1 4}$ & 0.188 & 0.087 & 0.036 & 0.446 \\
Parents play indoors (1 pw) & $\mathbf{0 . 7 5 5}$ & 0.233 & -0.038 & 0.007 & 0.374 \\
Evenings or weekend with family at & $\mathbf{0 . 5 9 9}$ & 0.016 & -0.067 & 0.001 & 0.637 \\
home (1 pw) & & & & 0.112 & 0.505 \\
Parents at the playground (1 pw) & 0.246 & $\mathbf{0 . 6 3 0}$ & 0.161 & -0.030 & 0.421 \\
Parents play active games (1 pw) & 0.526 & $\mathbf{0 . 5 4 9}$ & -0.015 & -0.125 & 0.428 \\
Sport with parents (1 pw) & 0.266 & $\mathbf{0 . 6 8 9}$ & -0.105 & -0.416 & 0.585 \\
Sport (1 pw) & -0.015 & $\mathbf{0 . 4 8 9}$ & 0.044 & 0.172 & 0.379 \\
Library (1 pw) & 0.024 & 0.323 & $\mathbf{0 . 6 9 8}$ & -0.215 & 0.349 \\
Religious activities (1 pw) & 0.026 & -0.230 & $\mathbf{0 . 7 4 3}$ & $\mathbf{0 . 7 4 2}$ & 0.419 \\
Watches TV/videos (1 h pd) & 0.034 & -0.114 & -0.124 & $\mathbf{0 . 7 7 4}$ & 0.391 \\
Uses computer (1 h pd) & -0.061 & 0.047 & 0.061 &
\end{tabular}

Correlation between the variables expressing activities and the extracted components (in columns). Higher correlations are in bold. ' $1 \mathrm{pw}$ ' stands for 'at least once per week'; ' $1 \mathrm{~h}$ pd' stands for 'at least $1 \mathrm{~h}$ per day' 
Table 11 Factor loading of the principal component analysis on activities at age 7 of the child (wave 4)

\begin{tabular}{|c|c|c|c|c|c|c|c|c|}
\hline Activities & $\begin{array}{l}\text { Activities } \\
\text { with parents }\end{array}$ & Sports & $\begin{array}{l}\text { Library/ } \\
\text { religious } \\
\text { activities }\end{array}$ & $\begin{array}{l}\text { Video- } \\
\text { screen }\end{array}$ & $\begin{array}{l}\text { Reading and } \\
\text { caring/tidying up }\end{array}$ & $\begin{array}{l}\text { Extra hours } \\
\text { at school }\end{array}$ & $\begin{array}{l}\text { School- } \\
\text { related } \\
\text { activities }\end{array}$ & Uniq. \\
\hline Parents read to child ( $1 \mathrm{pw})$ & 0.448 & 0.099 & -0.041 & -0.078 & 0.148 & 0.045 & 0.539 & 0.467 \\
\hline Parents tell story $(1 \mathrm{pw})$ & 0.531 & -0.192 & 0.196 & -0.045 & 0.190 & 0.045 & 0.131 & 0.585 \\
\hline Parents play music (1 pw) & 0.550 & -0.023 & -0.170 & -0.068 & 0.294 & 0.149 & 0.089 & 0.546 \\
\hline Parents draw (1 pw) & 0.713 & -0.202 & 0.057 & -0.058 & 0.088 & -0.039 & 0.129 & 0.419 \\
\hline Parents play indoors (1 pw) & 0.772 & 0.030 & -0.053 & 0.014 & 0.119 & -0.015 & 0.070 & 0.380 \\
\hline $\begin{array}{l}\text { Evenings or weekend with } \\
\text { family at home ( } 1 \mathrm{pw})\end{array}$ & 0.461 & 0.225 & -0.029 & 0.082 & 0.321 & -0.107 & -0.023 & 0.615 \\
\hline $\begin{array}{l}\text { Parents at the } \\
\text { playground ( } 1 \mathrm{pw})\end{array}$ & 0.592 & 0.093 & 0.238 & 0.036 & -0.148 & -0.002 & -0.130 & 0.544 \\
\hline $\begin{array}{l}\text { Parents play active } \\
\text { games ( } 1 \mathrm{pw})\end{array}$ & 0.754 & 0.223 & -0.013 & -0.043 & -0.032 & 0.006 & -0.069 & 0.375 \\
\hline Sport with parents $(1 \mathrm{pw})$ & 0.565 & 0.523 & -0.108 & 0.019 & 0.005 & -0.009 & 0.058 & 0.392 \\
\hline Sport with friends $(1 \mathrm{pw})$ & 0.088 & 0.714 & -0.154 & 0.111 & 0.077 & -0.087 & 0.157 & 0.408 \\
\hline Sport (1 pw) & 0.012 & 0.642 & 0.026 & -0.204 & 0.002 & 0.146 & 0.172 & 0.494 \\
\hline Club (1 pw) & -0.051 & 0.515 & 0.438 & -0.186 & 0.119 & 0.173 & -0.087 & 0.455 \\
\hline Library (1 pw) & 0.211 & -0.196 & 0.596 & 0.103 & 0.017 & 0.035 & 0.085 & 0.542 \\
\hline Religious activities (1 pw) & -0.086 & -0.021 & 0.735 & -0.076 & 0.137 & -0.173 & -0.067 & 0.393 \\
\hline Watches TV/videos $(1 \mathrm{~h} \mathrm{pd})$ & -0.052 & -0.057 & -0.070 & 0.803 & 0.035 & 0.017 & -0.020 & 0.342 \\
\hline Uses computer ( $1 \mathrm{~h} \mathrm{pd})$ & -0.005 & 0.009 & 0.013 & 0.778 & -0.088 & -0.002 & -0.016 & 0.386 \\
\hline Reads (1 pw) & 0.086 & 0.107 & 0.168 & -0.036 & 0.719 & 0.003 & 0.098 & 0.425 \\
\hline $\begin{array}{l}\text { Tidying up and caring for } \\
\text { pets ( } 1 \mathrm{pw})\end{array}$ & 0.179 & -0.016 & 0.008 & -0.086 & 0.592 & 0.055 & 0.156 & 0.582 \\
\hline After school class (1 pw) & -0.021 & 0.116 & 0.012 & -0.026 & 0.016 & 0.779 & 0.088 & 0.371 \\
\hline Before school class (1 pw) & 0.017 & -0.061 & -0.093 & 0.037 & 0.006 & 0.805 & -0.070 & 0.333 \\
\hline Homework ( $1 \mathrm{~h}$ pd) & -0.005 & 0.179 & -0.032 & 0.014 & 0.132 & -0.013 & 0.748 & 0.390 \\
\hline Extra classes $(1 \mathrm{pw})$ & -0.021 & -0.016 & 0.452 & -0.115 & -0.406 & 0.026 & 0.461 & 0.404 \\
\hline
\end{tabular}

Correlation between the variables expressing activities and the extracted components. Higher correlations are in bold. ' $1 \mathrm{pw}$ ' stands for 'at least once per week'; ' $1 \mathrm{~h}$ pd' stands for 'at least $1 \mathrm{~h}$ per day'

Table 12 Factor loading of the principal component analysis on activities at age 11 of the child (wave 5)

\begin{tabular}{|c|c|c|c|c|c|c|c|c|}
\hline Activities & $\begin{array}{l}\text { Activities } \\
\text { with parents }\end{array}$ & Sports & $\begin{array}{l}\text { Library/ } \\
\text { religious } \\
\text { activities }\end{array}$ & $\begin{array}{l}\text { Video- } \\
\text { screen time }\end{array}$ & $\begin{array}{l}\text { Reading and } \\
\text { caring/tidying up }\end{array}$ & $\begin{array}{l}\text { Extra hours } \\
\text { at school }\end{array}$ & $\begin{array}{l}\text { School-related } \\
\text { activities }\end{array}$ & Uniq. \\
\hline $\begin{array}{l}\text { Parents play } \\
\text { indoors ( } 1 \mathrm{pw})\end{array}$ & 0.852 & 0.032 & 0.064 & 0.054 & 0.085 & 0.028 & -0.024 & 0.258 \\
\hline $\begin{array}{l}\text { Parents talk to } \\
\text { child (1 pw) }\end{array}$ & 0.583 & -0.051 & -0.413 & -0.047 & 0.052 & 0.086 & 0.160 & 0.449 \\
\hline $\begin{array}{l}\text { Parents play active } \\
\text { games ( } 1 \mathrm{pw})\end{array}$ & 0.785 & 0.185 & 0.157 & -0.065 & 0.010 & -0.008 & -0.023 & 0.320 \\
\hline $\begin{array}{l}\text { Sport with } \\
\text { friends (1 pw) }\end{array}$ & 0.101 & 0.795 & -0.140 & -0.084 & 0.033 & 0.051 & 0.064 & 0.324 \\
\hline Sport (1 pw) & 0.017 & 0.623 & -0.115 & -0.143 & -0.186 & 0.291 & 0.236 & 0.403 \\
\hline Bike (1 pw) & 0.127 & 0.656 & 0.206 & 0.115 & 0.169 & -0.136 & -0.178 & 0.418 \\
\hline Library (1 pw) & 0.202 & -0.065 & 0.742 & -0.062 & 0.012 & 0.105 & 0.017 & 0.388 \\
\hline $\begin{array}{l}\text { Religious } \\
\text { activities (1 pw) }\end{array}$ & -0.022 & -0.130 & 0.504 & -0.112 & 0.238 & 0.007 & 0.462 & 0.446 \\
\hline $\begin{array}{l}\text { Watches TV/videos } \\
(1 \mathrm{~h} \text { pd })\end{array}$ & -0.020 & -0.062 & -0.146 & 0.718 & 0.040 & 0.111 & 0.051 & 0.442 \\
\hline
\end{tabular}


Table 12 continued

\begin{tabular}{|c|c|c|c|c|c|c|c|c|}
\hline Activities & $\begin{array}{l}\text { Activities } \\
\text { with parents }\end{array}$ & Sports & $\begin{array}{l}\text { Library/ } \\
\text { religious } \\
\text { activities }\end{array}$ & $\begin{array}{l}\text { Video- } \\
\text { screen time }\end{array}$ & $\begin{array}{l}\text { Reading and } \\
\text { caring/tidying up }\end{array}$ & $\begin{array}{l}\text { Extra hours } \\
\text { at school }\end{array}$ & $\begin{array}{l}\text { School-related } \\
\text { activities }\end{array}$ & Uniq. \\
\hline $\begin{array}{l}\text { Uses computer } \\
(1 \mathrm{~h} \mathrm{pd})\end{array}$ & 0.029 & -0.026 & 0.045 & 0.739 & -0.132 & -0.031 & -0.056 & 0.429 \\
\hline Plays music (1 pw) & 0.084 & 0.079 & 0.030 & -0.451 & -0.159 & 0.117 & 0.234 & 0.689 \\
\hline $\begin{array}{l}\text { Tidying up and } \\
\text { caring for pets }\end{array}$ & 0.189 & 0.064 & -0.234 & -0.274 & 0.644 & 0.065 & 0.151 & 0.389 \\
\hline $\begin{array}{l}\text { Looks after } \\
\text { elderly ( } 1 \mathrm{pw})\end{array}$ & 0.025 & 0.008 & 0.164 & 0.075 & 0.794 & 0.009 & -0.040 & 0.335 \\
\hline $\begin{array}{l}\text { After school } \\
\text { class }(1 \mathrm{pw})\end{array}$ & 0.041 & 0.033 & -0.011 & -0.012 & -0.027 & 0.811 & 0.099 & 0.329 \\
\hline $\begin{array}{l}\text { Before school } \\
\text { class }(1 \mathrm{pw})\end{array}$ & 0.012 & 0.054 & 0.097 & 0.056 & 0.086 & 0.769 & -0.157 & 0.360 \\
\hline Homework (1 h pd) & 0.129 & 0.162 & -0.249 & -0.004 & 0.005 & -0.010 & 0.620 & 0.511 \\
\hline Extra classes (1 pw) & -0.097 & 0.024 & 0.216 & -0.020 & 0.007 & -0.054 & 0.659 & 0.506 \\
\hline
\end{tabular}

Correlation between the variables expressing activities and the extracted components. Higher correlations are in bold. ' $1 \mathrm{pw}$ ' stands for 'at least once per week'; ' $1 \mathrm{~h}$ pd' stands for 'at least $1 \mathrm{~h}$ per day'

Table 13 Control variables

Age 7 (wave 4)

Environmental variables (panel A)

Mother in the $\mathrm{HH}$

$0.99(0.09)$

$0.77(0.42)$

$0.05(0.21)$

Stepfather in the $\mathrm{HH}$

At least 1 sibling in the $\mathrm{HH}$

At least 1 grandparent in the $\mathrm{HH}$

At least 1 other adult in the $\mathrm{HH}$

Mother's hours of work (per week)

$0.88(0.32)$

$0.06(0.24)$

$0.06(0.23)$

16.36 (14.92)

Father's hours of work (per week)

39.31 (15.34)

Parental investments variables (panel B)

Mother with tertiary education

$0.40(0.49)$

$0.40(0.49)$

$0.42(0.49)$

Father with tertiary education

Child breastfed for at least 1 month

Mother was back to work by 6 months of the child

Father looks after the child on his own

Formal childcare when the child was 30 months old

Other child, parents, household's characteristics (panel C)

Age child (in months)

$0.49(0.50)$

$0.39(0.49)$

$0.61(0.49)$

$0.30(0.46)$

$86.71(2.95)$

133.97 (3.89)

Girl

Birthweight

British

Had injuries (9 months old)

Ever gone to hospital (9 months old)
$0.49(0.50)$

$0.50(0.50)$

$3.39(0.58)$

$3.39(0.58)$

$0.87(0.33)$

$0.88(0.33)$

$0.09(0.30)$

$0.08(0.29)$

$0.17(0.55)$

0.17 (0.56) 
Table 13 continued

\begin{tabular}{lcc}
\hline & Age 7 (wave 4) & Age 11 (wave 5) \\
\hline Communicative development (9 months old) & $-0.05(0.97)$ & $-0.06(0.97)$ \\
Motor development (9 months old) & $0.02(0.96)$ & $0.02(0.96)$ \\
Motion development (9 months old) & $0.07(0.82)$ & $0.07(0.81)$ \\
Cognitive development, lag & $0.11(0.95)$ & $0.11(0.95)$ \\
Number of siblings at birth & $0.90(1.10)$ & $0.89(1.00)$ \\
Mother locus of control & $0.80(0.40)$ & $0.81(0.39)$ \\
Mother conflicts (PIANTA scale) & $17.05(5.85)$ & $17.01(5.82)$ \\
Mother closeness (PIANTA scale) & $33.62(2.25)$ & $33.65(2.22)$ \\
Mother being neurotic (OCEAN scale) & $23.63(4.80)$ & $23.64(4.78)$ \\
Mother being extrovert (OCEAN scale) & $19.56(4.61)$ & $19.55(4.61)$ \\
Maternal mental well-being & $3.00(3.74)$ & $3.77(4.18)$ \\
Paternal mental well-being & $2.87(3.33)$ & $3.70(3.73)$ \\
Presence of new-borns & $0.11(0.32)$ & $0.05(0.21)$ \\
Weekly HH equivalent income & $343(194)$ & $422(160)$ \\
Holiday outside UK & $0.50(0.50)$ & $0.47(0.50)$ \\
England & $0.62(0.49)$ & $0.62(0.49)$ \\
Wales & $0.16(0.36)$ & $0.15(0.36)$ \\
Scotland & $0.12(0.33)$ & $0.12(0.32)$ \\
Northern Ireland & $0.10(0.30)$ & $0.10(0.30)$ \\
Observations & 10,570 & 9438 \\
\hline
\end{tabular}

HH stands for household. Child's development variables (communicative, motor and motion) are factor points derived from principal component analyses (see Table 14); cognitive development reports factor points derived from principal component analyses of the three available cognitive outcomes for the previous wave (see Table 15) 
Table 14 Factor loading of the principal component analysis on development indicators in the first year of life (wave 1)

\begin{tabular}{lccc}
\hline Ability & $\begin{array}{l}\text { Communication } \\
\text { development }\end{array}$ & $\begin{array}{l}\text { Motor } \\
\text { development }\end{array}$ & $\begin{array}{c}\text { Motion } \\
\text { development }\end{array}$ \\
\hline Smiles & -0.133 & 0.068 & $\mathbf{0 . 4 2 4}$ \\
Sits up & 0.058 & $\mathbf{0 . 4 9 6}$ & 0.358 \\
Stands up holding on & 0.171 & $\mathbf{0 . 7 5 5}$ & 0.016 \\
Hands together & $\mathbf{0 . 3 9 4}$ & -0.008 & 0.255 \\
Grabs objects & -0.036 & 0.048 & $\mathbf{0 . 6 6 5}$ \\
Holds small objects & 0.218 & 0.154 & $\mathbf{0 . 4 2 3}$ \\
Passes a toy & 0.145 & -0.036 & $\mathbf{0 . 6 3 7}$ \\
Walks a few steps & 0.326 & $\mathbf{0 . 3 5 2}$ & -0.160 \\
Gives toys & $\mathbf{0 . 5 7 9}$ & 0.206 & 0.186 \\
Waves bye-bye & $\mathbf{0 . 6 5 7}$ & 0.152 & 0.058 \\
Extends arms & $\mathbf{0 . 3 8 0}$ & 0.309 & 0.122 \\
Nods for yes & $\mathbf{0 . 6 1 1}$ & -0.100 & -0.113 \\
Can move from place to place & -0.082 & $\mathbf{0 . 6 6 3}$ & -0.014 \\
\hline
\end{tabular}

Correlation between the variables expressing abilities and the extracted components. Higher correlations are in bold

Table 15 Factor loading of the principal component analysis on children's cognitive tests (waves 3 and 4)

\begin{tabular}{lll}
\hline Tests_age 5 & Cognitive skills & Uniqueness \\
\hline Naming vocabulary & 0.743 & 0.448 \\
Pattern construction & 0.761 & 0.420 \\
Picture similarity & 0.741 & 0.451 \\
Tests_age 7 & Cognitive skills & Uniqueness \\
Word Reading & 0.770 & 0.407 \\
Pattern construction & 0.745 & 0.444 \\
Maths & 0.852 & 0.274 \\
\hline
\end{tabular}

Correlation between the variables expressing cognitive skills and the extracted component 


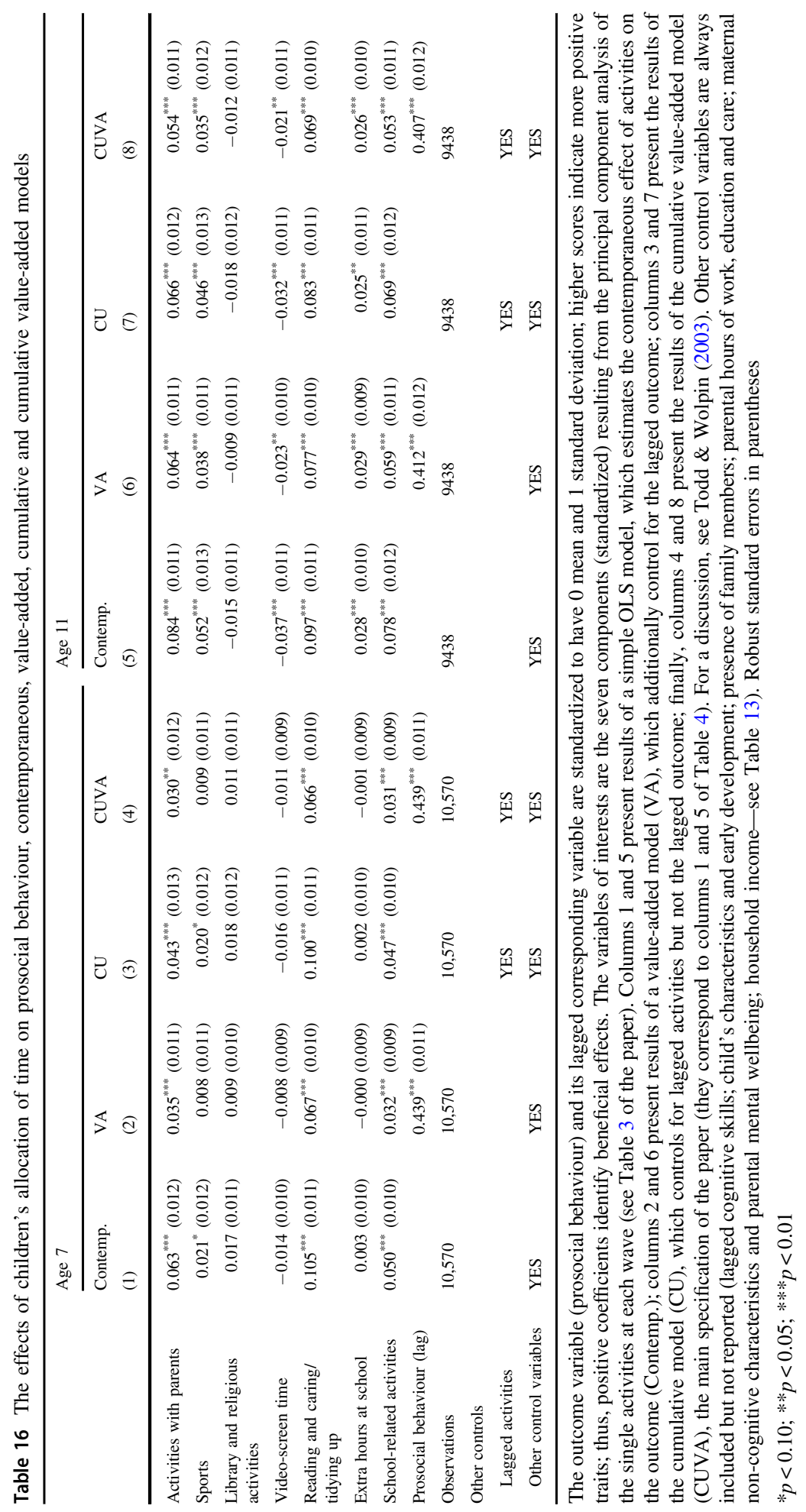




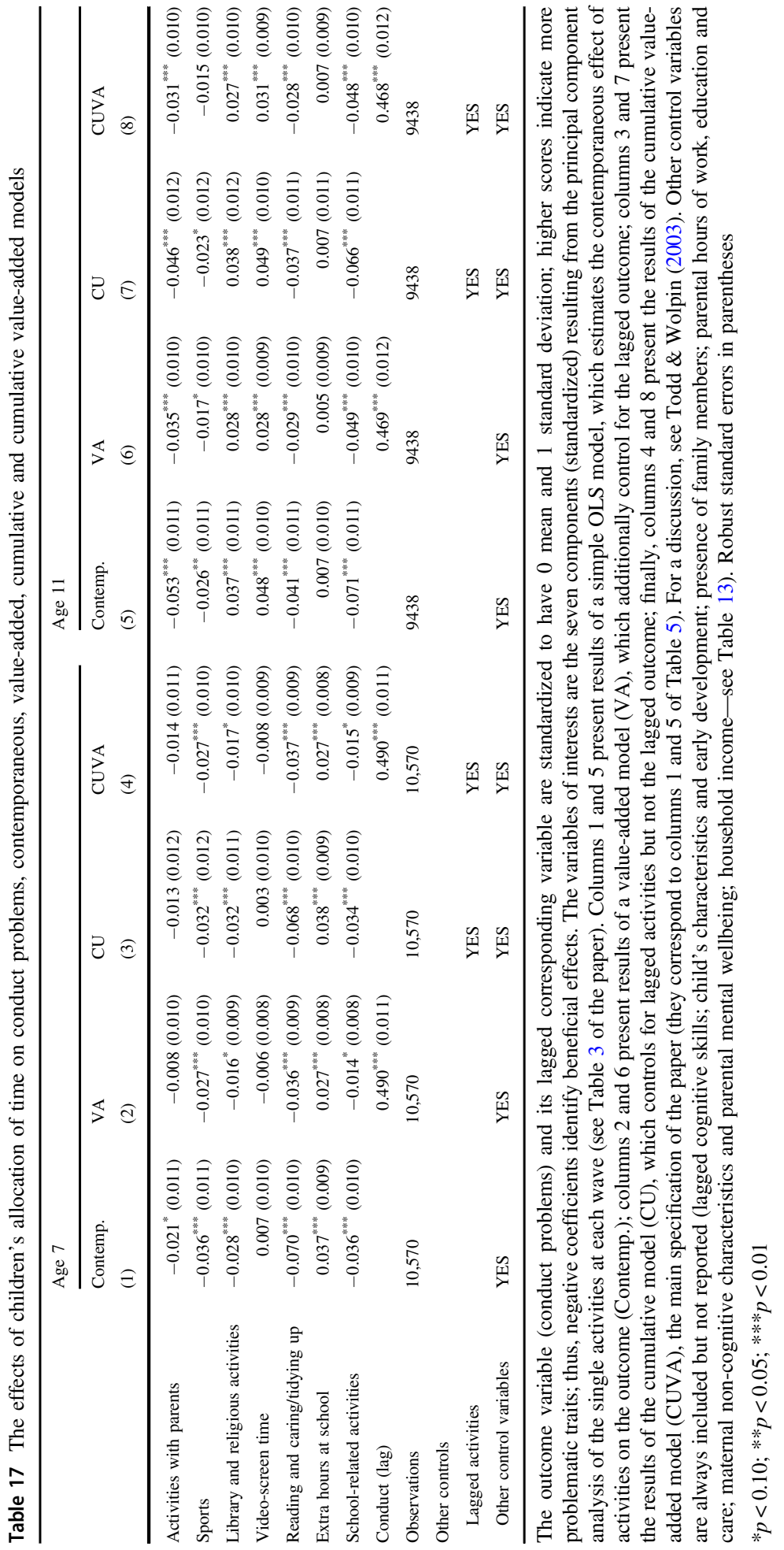




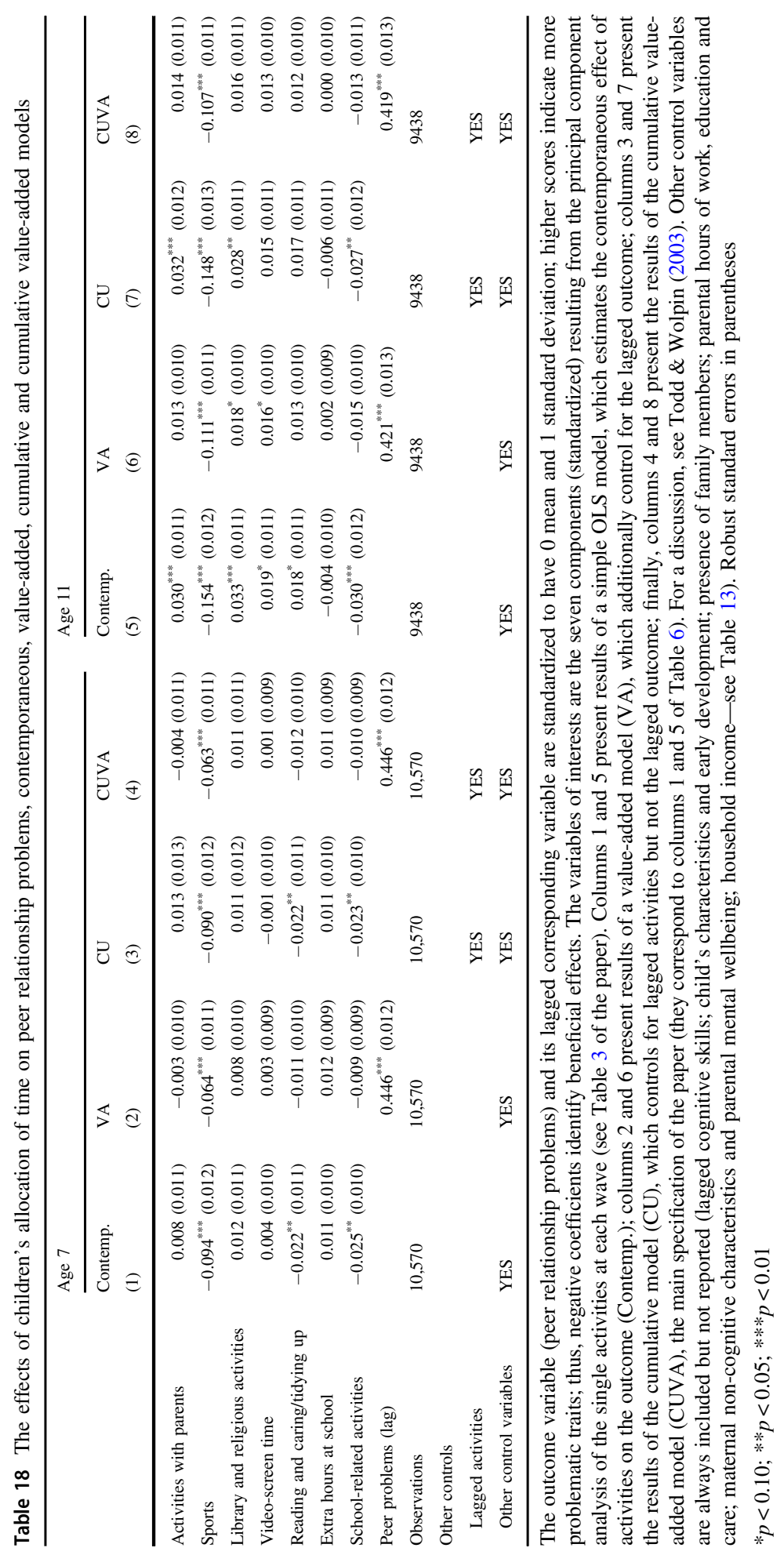




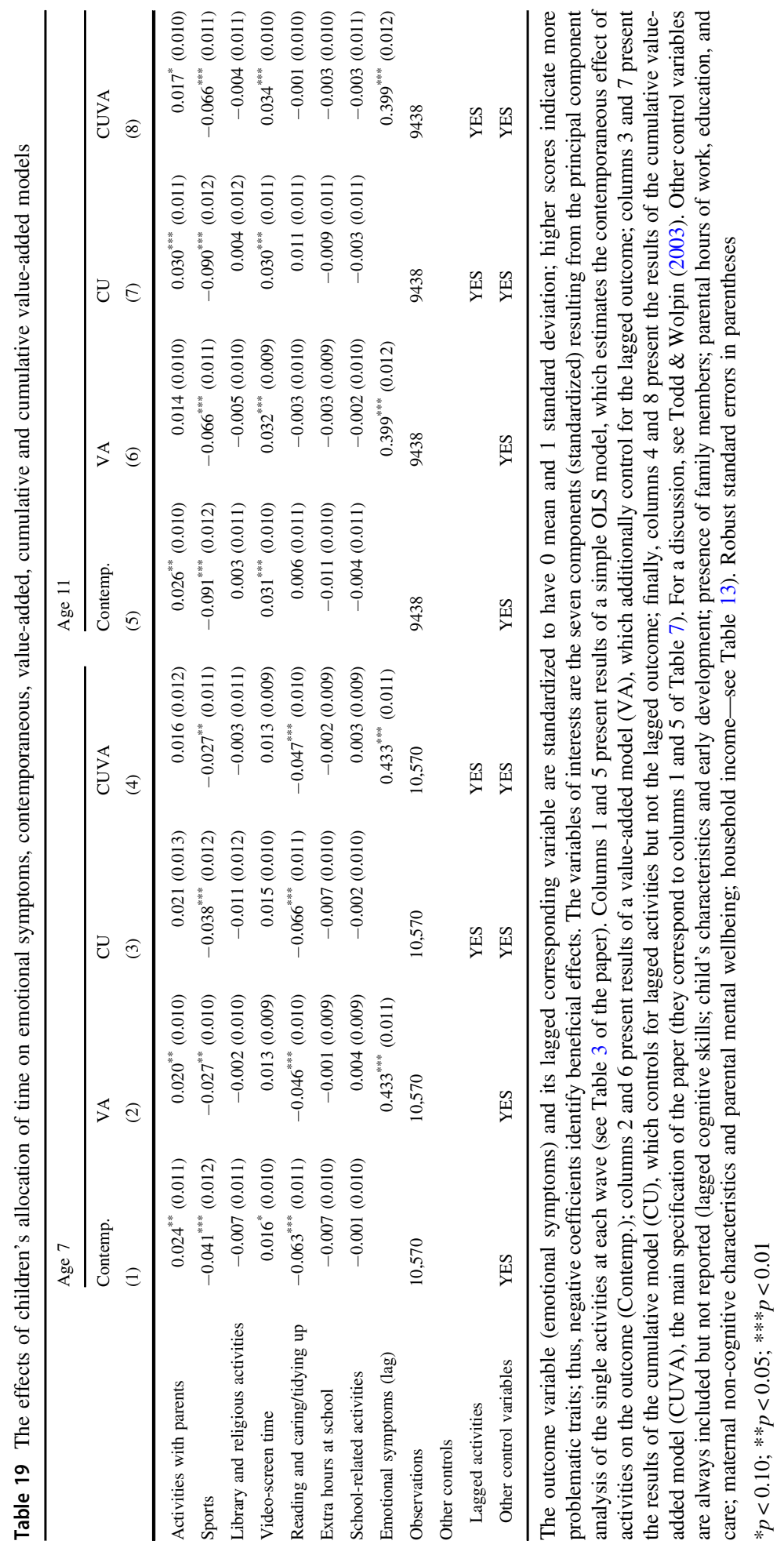




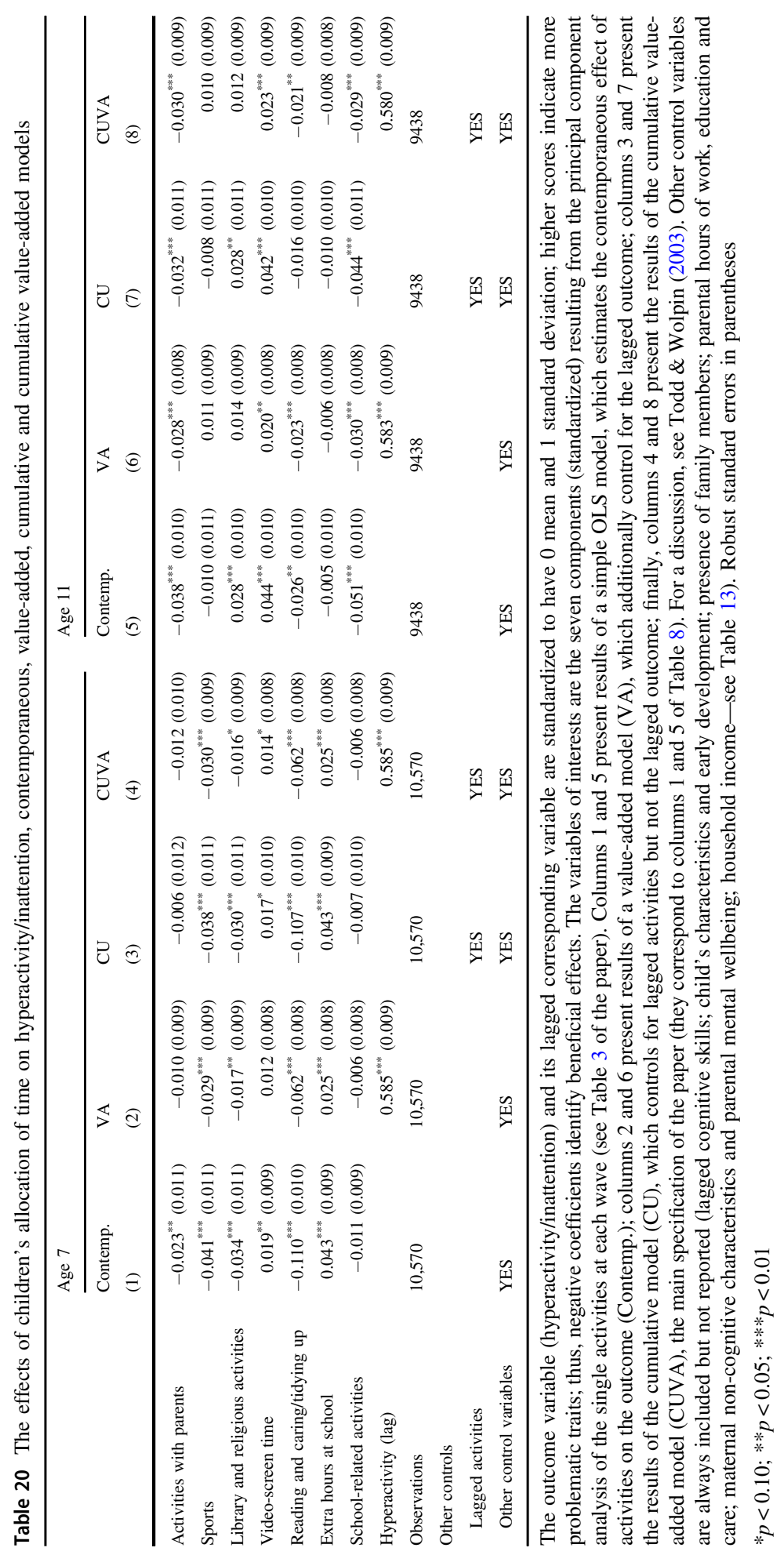



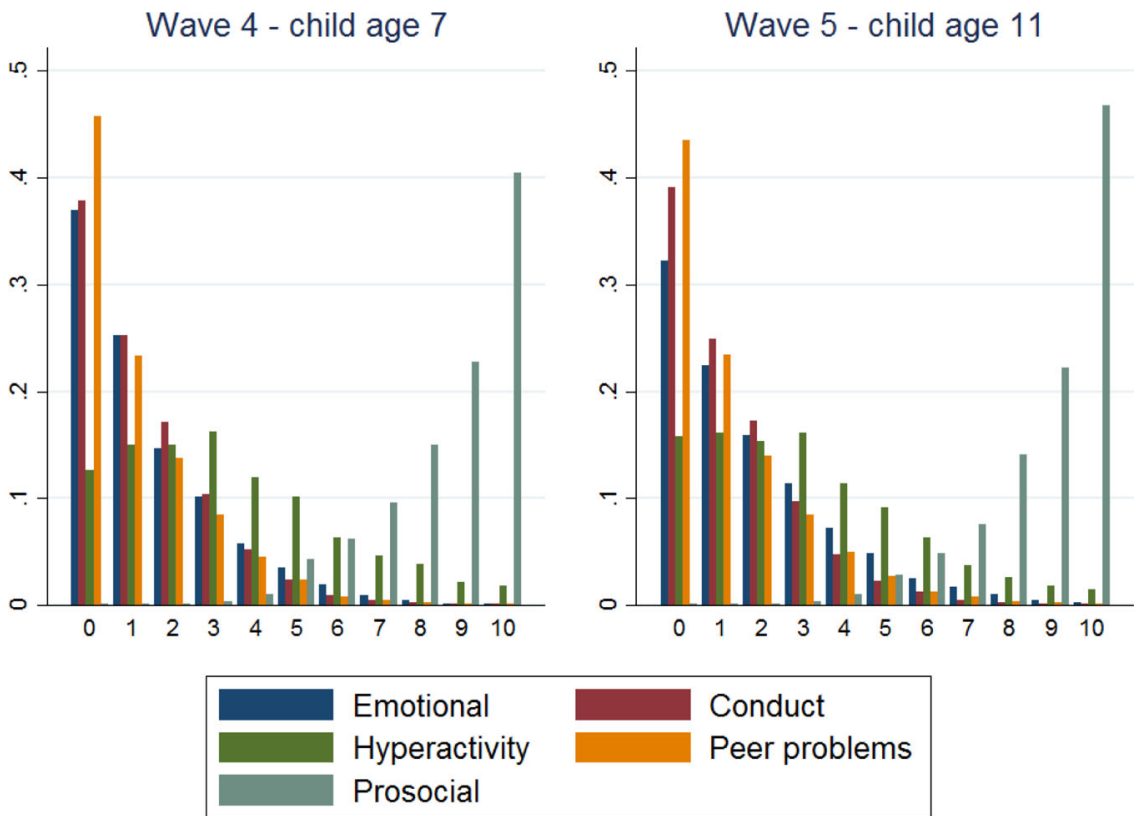

Fig. 1 Children's socio-emotional skills. The five colours represent the five socio-emotional indicators (emotional symptoms, conduct problems, hyperactivity/inattention, peer relationship problems, prosocial behaviour). Each indicator goes from 0 to 10, depending on the answers the caregivers give to the five questions for each child's non-cognitive dimension. 0 means 'absence of problems' and 10 'presence of all problems' for the first four indicators, while 10 means 'absence of problems' and 0 'presence of all problems' for prosocial behaviour

\section{Appendix B: Strengths and Difficulties Questionnaire}

The Strength and Difficulties questionnaire (SDQ) is a brief emotional and behavioural screening questionnaire for children and young people (aged 4 to 16 years old), first developed by Goodman (1997) to measure psychological adjustment. One version of the questionnaire is designed to be filled out individually by parents, teachers, and older children. It can be used for various purposes, including clinical assessment, evaluation of outcomes, research and screening. The questionnaire used in the paper, from the Millennium Cohort Study, is filled out individually by the parents at different waves.

The SDQ contains 25 items, divided across 5 scales of 5 items each (the emotional symptoms subscale, conduct problems subscale, hyperactivity/inattention subscale, peer relationships problem subscale, and prosocial behaviour subscale). The five subscales have been refined through exploratory factor analyses (Goodman, 1997) and supported by subsequent analysis.

Parents are asked to think about the behaviour of their child over the previous six months, and for each item, answer according to a 3-point response scale ('Not true' $=0$, 'Somewhat true' $=1$, 'Certainly true' $=2$ ). The groups of five answers are combined into a single total score for each socio-emotional dimension, ranging from 
Table 21 Normative data for the Strengths and Difficulties Questionnaire, selected countries

\begin{tabular}{lccccccccc}
\hline & Australia & \multicolumn{3}{c}{ Great Britain } & & Japan & U.S.A. & \multicolumn{3}{c}{$\begin{array}{l}\text { MCS UK } \\
\text { Our sample }\end{array}$} \\
\hline & & & & & & & & \\
Age group & $7-17$ & $7-10$ & $5-15$ & $5-10$ & $4-15$ & $4-7$ & $8-10$ & 7 & 11 y.o. \\
Emotional symptoms & $2.1(2.0)$ & $2.3(2.0)$ & $1.9(2.0)$ & $1.9(2.0)$ & $1.4(1.7)$ & $1.6(1.8)$ & $1.5(1.9)$ & $1.5(1.7)$ & $1.8(2.0)$ \\
Conduct problems & $1.5(1.6)$ & $1.3(1.5)$ & $1.6(1.7)$ & $1.6(1.7)$ & $1.8(1.5)$ & $1.3(1.6)$ & $1.3(1.7)$ & $1.3(1.5)$ & $1.3(1.5)$ \\
Hyperactivity/inattention & $3.1(2.4)$ & $2.6(2.2)$ & $3.5(2.6)$ & $3.6(2.7)$ & $2.8(2.1)$ & $2.8(2.5)$ & $2.9(2.6)$ & $3.3(2.5)$ & $3.0(2.4)$ \\
Peer problems & $1.6(1.9)$ & $1.5(1.9)$ & $1.5(1.7)$ & $1.4(1.7)$ & $1.4(1.6)$ & $1.4(1.5)$ & $1.5(1.6)$ & $1.1(1.5)$ & $1.3(1.6)$ \\
Prosocial behaviour & $8.3(1.7)$ & $8.7(1.6)$ & $8.6(1.6)$ & $8.6(1.6)$ & $6.3(2.2)$ & $8.6(1.8)$ & $8.8(2.7)$ & $8.6(1.6)$ & $8.9(1.5)$ \\
Observations & 910 & 197 & 10,298 & 5,855 & 4800 & 9878 & 2064 & 10,570 & 9438 \\
\hline
\end{tabular}

Standard deviation in parentheses. Normative data from Mellor (2005) (Australia), Meltzer et al. (2000) (Great Britain), Moriwaki \& Kamio (2014) (Japan), National Health Interview Survey (NHIS) for the USA

0 to 10 . Lower scores identify positive traits for the first four dimensions, while a higher score identifies more positive traits in terms of prosocial behaviour.

Table 21 below presents compares the normative data of the SDQ for some countries, compared to our sample.

The 25 questions of the questionnaire are as follows (see Johnson et al., 2015):

[Cohort child name]

(1) Considerate of others' feelings

(2) Restless, overactive, cannot stay still for long

(3) Complains of headaches/stomach-aches/sickness

(4) Shares readily with others

(5) Often has temper tantrums

(6) Tends to play alone

(7) Generally obedient

(8) Often seems worried

(9) Helpful if someone is hurt, upset or ill

(10) Constantly fidgeting

(11) Has at least one good friend

(12) Fights with or bullies other children

(13) Often unhappy

(14) Generally liked by other children

(15) Easily distracted

(16) Nervous or clingy in new situations

(17) Kind to younger children

(18) Often argumentative with adults

(19) Picked on or bullied by other children

(20) Often volunteers to help others

(21) Can stop and think before acting

(22) Can be spiteful to others

(23) Gets on better with adults

(24) Many fears, easily scared

(25) Sees tasks through to the end 


\section{References}

Algan, Y., E. Beasley, F. Vitaro, \& R. E. Tremblay (2014). The impact of non-cognitive skills training on academic and non-academic trajectories: From childhood to early adulthood, Sciences Po Working Paper

Almlund, M., Duckworth, A., Heckman, J., \& Kautz, T. (2011). Personality psychology and economics. Handbook of the Economics of Education, 4, 1-181

Altonji, J. G., Elder, T. E., \& Taber, C. R. (2005). Selection on observed and unobserved variables: assessing the effectiveness of catholic schools. Journal of Political Economy, 113(1), 151-184

Anderson, R. C., Wilson, P. T., \& Fielding, L. G. (1988). Growth in reading and how children spend their time outside of school. Reading Research Quarterly, 23(3), 285-303

Andrabi, T., Das, J., Khwaja, A. I., \& Zajonc, T. (2011). Do value-added estimates add value? Accounting for learning dynamics. American Economic Journal: Applied Economics, 3(3), 29-54

Arellano, M., \& Bond, S. (1991). Some tests of specification for panel data: Monte Carlo evidence and an application to employment equations. The Review of Economic Studies, 58(2), 277-297

Attanasio, O., Blundell, R., Conti, G., \& Mason, G. (2020). Inequality in socio-emotional skills: a crosscohort comparison. Journal of Public Economics, 191, 104171

Borra, C., Iacovou, M., \& Sevilla, A. (2012). The effect of breastfeeding on children's cognitive and noncognitive development. Labour Economics, 19(4), 496-515

Brilli, Y., Del Boca, D., \& Pronzato, C. (2016). Does child care availability play a role in maternal employment and children's development? Evidence from Italy. Review of Economics of the Household, 14(1), 27-51

Caetano, C. (2015). A test of exogeneity without instrumental variables in models with bunching. Econometrica, 83(4), 1581-1600

Caetano, G., Kinsler, J., \& Teng, H. (2019). Towards causal estimates of children's time allocation on skill development. Journal of Applied Econometrics, 34(4), 588-605

Callanan, M., Laing, K., Chanfreau, J., Paylor, J. Skipp, A. Tanner, E., \& Todd, L. (2016). The value of after school clubs for disadvantaged children. NatCen Social Research and Newcastle University

Card, D., \& Krueger, A. B. (1992). Does school quality matter? Returns to education and the characteristics of public schools in the United States. Journal of Political Economy, 100(1), 1-40

Carneiro, P., \& Rodriguez, M. (2009). Evaluating the effect of maternal time on child development using the generalized propensity score. Institute for the Study of Labor, 12th IZA European Summer School in Labor Economics

Case, A., Fertig, A., \& Paxson, C. (2005). The lasting impact of childhood health and circumstance. Journal of Health Economics, 24(2), 365-389

Cuffe, H. E., Waddell, G. R., \& Bignell, W. (2017). Can school sports reduce racial gaps in truancy and achievement? Economic Inquiry, 55(4), 1966-1985

Cunha, F., \& Heckman, J. J. (2008). Formulating, identifying and estimating the technology of cognitive and noncognitive skill formation. Journal of Human Resources, 43(4), 738-782

Cunha, F., Elo, I., \& Culhane, J. (2013). Eliciting maternal expectations about the technology of cognitive skill formation. NBER Working Paper 19144

Del Boca, D., Monfardini, C., \& Nicoletti, C. (2017). Parental and child time investments and the cognitive development of adolescents. Journal of Labor Economics, 35(2), 565-608

Del Boca, D., Piazzalunga, D., \& Pronzato, C. (2018). The role of grandparenting in early childcare and child outcomes. Review of Economics of the Household, 16(2), 477-512

Del Bono, E., Francesconi, M., Kelly, Y., \& Sacker, A. (2016). Early maternal time and early child outcomes. The Economic Journal, 126(596), F96-135

Deming, D. J., Hastings, J. S., Kane, T. J., \& Staiger, D. O. (2014). School choice, school quality, and postsecondary attainment. American Economic Review, 104(3), 991-1013

Ding, W., \& Lehrer, S. F. (2007). Do peers affect student achievement in china's secondary schools? The Review of Economics and Statistics, 89(2), 300-312

Doyle, O., Harmon, C., Heckman, J. J., Logue, C., \& Moon, S. H. (2017). Early skill formation and the efficiency of parental investment: a randomized controlled trial of home visiting. Labour Economics, 45, 40-58

Duncan, G. J., \& Magnuson, K. (2013). Investing in preschool programs. Journal of Economic Perspectives, 27(2), 109-32

Durlak, J. A., Weissberg, R. P., Dymnicki, A. B., Taylor, R. D., \& Schellinger, K. (2011). The impact of enhancing students' social and emotional learning: a meta-analysis of school-based universal interventions. Child Development, 82, 405-432 
Eccles, J. S., Barber, B. L., Stone, M., \& Hunt, J. (2003). Extracurricular activities and adolescent development. Journal of Social Issues, 59(4), 865-889

Elango, S., García, J. L., Heckman, J. J., \& Hojman, A. (2016). Early ch ildhood education. In R. A. Moffitt (ed.), Economics of means-tested transfer programs in the United States, vol. 2. Chicago, IL: University of Chicago Press

Emmons, R. A. (2003). Personal goals, life meaning, and virtue: wellsprings of a positive life. In C. L. M. Keyes \& J. Haidt (Eds.), Flourishing: positive psychology and the life well-lived (pp. 105-128). Washington, DC: American Psychological Association Books

Fairlie, R. W., \& Kalil, A. (2017). The effects of computers on children's social development and school participation: Evidence from a randomized control experiment. Economics of Education Review, 57, $10-19$

Felfe, C., Steinmayr, A., \& Lechner, M. (2016). Sports and child development. PLoS ONE, 11(5), e0151729 https://doi.org/10.1371/journal.pone.0151729

Fiorini, M., \& Keane, M. P. (2014). How the allocation of children's time affects cognitive and noncognitive development. Journal of Labor Economics, 32(4), 787-836

Fletcher, J. M., \& Wolfe, B. (2016). The importance of family income in the formation and evolution of non-cognitive skills in childhood. Economics of Education Review, 54, 143-154

Francesconi, M., Jenkins, S. P., \& Siedler, T. (2010). Childhood family structure and schooling outcomes: evidence for Germany. Journal of Population Economics, 23, 1073-1103

Gentzkow, M., \& Shapiro, J. M. (2008). Preschool television viewing and adolescent test scores: historical evidence from the Coleman study. The Quarterly Journal of Economics, 123(1), 279-323

Goodman, R. (1997). The strengths and difficulties questionnaire: a research note. Journal of Child Psychology and Psychiatry, 38(5), 581-586

Hale, L., Berger, L. M., Le Bourgeois, M. K., \& Brooks-Gunn, J. (2011). A longitudinal study of preschoolers' language-based bedtime routines, sleep duration, and well-being. Journal of Family Psychology, 25(3), 423-433

Hansen, K. (2012). Millennium cohort study first, second, third and fourth surveys: a guide to the datasets, Centre for Longitudinal Studies. London: Institute of Education, University of London

Heckman, J. J., \& Kautz, T. (2013). Fostering and measuring skills: Interventions that improve character and cognition. NBER Working Paper 19656

Heckman, J. J., \& Rubinstein, Y. (2001). The importance of noncognitive skills: lessons from the GED testing program. American Economic Review, 91(2), 145-149

Hernæs, Ø., Markussen, S., \& Røed, K. (2019). Television, cognitive ability, and high school completion. Journal of Human Resources, 54(2), 371-400

Hernández-Alava, M., \& Popli, G. (2017). Children's development and parental input: evidence from the UK millennium cohort study. Demography, 54(2), 485-511

Hill, M., Yeung, W., \& Duncan, G. (2001). Childhood family structure and young adult behaviors. Journal of Population Economics, 14, 271-299

Hille, A., \& Schupp, J. (2015). How learning a musical instrument affects the development of skills. Economics of Education Review, 44, 56-82

Hofferth, S., \& Sandberg, J. F. (2001). How American children spend their time. Journal of Marriage and Family, 63(2), 295-308

Hsin, A., \& Felfe, C. (2014). When does time matter? Maternal employment, children's time with parents, and child development. Demography, 4, 1867-94

Huang, F., \& Lee, M. J. (2010). Dynamic treatment effect analysis of TV effects on child cognitive development. Journal of Applied Econometrics, 25(3), 392-419

Johnson, J, Atkinson, M. \& \& Rosenberg, R. 2015). Millennium Cohort Study. Psychological, developmental and health inventories, User guide to the data. London: Centre for Longitudinal Studies, Institute of Education, University of London. https://cls.ucl.ac.uk/wp-content/uploads/2018/08/ Guide-to-Psychological-Inventories-in-MCS3.pdf

Kalb, G., \& Van Ours, J. C. (2014). Reading to young children: a head-start in life? Economics of Education Review, 40, 1-24

Kearney, M. S., \& Levine, P. B. (2019). Early childhood education by television: lessons from Sesame street. American Economic Journal: Applied Economics, 11(1), 318-50

Kosse, F., Deckers, T., Pinger, P., Schildberg-Hörisch, H., \& Falk, A. (2020). The formation of prosociality: causal evidence on the role of social environment. Journal of Political Economy, 128(2), 434-467

Lechner, M. (2009). Long-run labour market and health effects of individual sports activities. Journal of Health Economics, 28(4), 839-854 
Leschied, A., Chiodo, D., Nowicki, E., \& Rodger, S. (2008). Childhood predictors of adult criminality: a meta-analysis drawn from the prospective longitudinal literature. Canadian Journal of Criminology and Criminal Justice, 50(4), 435-467

Lichtenberg, J. D., Lackmann, F. M., \& Fosshage, J. L. (2012). I sistemi motivazionali: una prospettiva dinamica. Bologna: Il Mulino

Lundberg, O. (1993). The impact of childhood living conditions on illness and mortality in adulthood. Social Science and Medicine, 36(8), 1047-1052

Mellor, D. (2005). Normative data for the Strengths and Difficulties Questionnaire in Australia. Australian Psychologist, 40, 215-222

Meltzer, H., Gatward, R., Goodman, R., \& Ford, F. (2000). Mental health of children and adolescents in Great Britain. London: The Stationery Office

Mendolia, S., Paloyo, A., \& Walker, I. (2019). Intrinsic religiosity, personality traits, and adolescent risky behaviors. BE Journal of Economic Analysis and Policy, 19(3), 20180311-1-20180311-16

Mittler, P. (1971). The study of twins. Baltimore: Penguin Books

Moriwaki, A., \& Kamio, Y. (2014). Normative data and psychometric properties of the Strengths and Difficulties Questionnaire among Japanese school-aged children. Child and Adolescent Psychiatry and Mental Health, 8(1), 1 https://doi.org/10.1186/1753-2000-8-1

Moroni, G. Nicoletti, C., \& Tominey, E. (2019). Child socio-emotional skills: the role of parental inputs. IZA Discussion Paper 12432

Mowrer, E. R. (1954). Some factors in the affectional adjustment of twins. American Sociological Review, 19(4), 468-471

Munasib, A., \& Bhattacharya, S. (2010). Is the 'Idiot's Box' raising idiocy? Early and middle childhood television watching and child cognitive outcome. Economics of Education Review, 29(5), 873-883

Nuttall, A. K., Valentino, K., Wang, L., Lefever, J. B., \& Borkowski, J. G. (2015). Maternal history of parentification and warm responsiveness: the mediating role of knowledge of infant development. Journal of Family Psychology, 29(6), 863-872

Oster, E. (2019). Unobservable selection and coefficient stability: theory and evidence. Journal of Business \& Economic Statistics, 37(2), 187-204

Pfeifer, C., \& Cornelißen, T. (2010). The impact of participation in sports on educational attainment: New evidence from Germany. Economics of Education Review, 29(1), 94-103

Prevoo, T., \& ter Weel, B. (2015). The importance of early conscientiousness for socio-economic outcomes: evidence from the British Cohort Study. Oxford Economic Papers, 67(4), 918-948

Ransom, M. R., \& Ransom, T. (2018). Do high school sports build or reveal character? Bounding causal estimates of sports participation. Economics of Education Review, 64, 75-89

Rees, D. I., \& Sabia, J. J. (2010). Sports participation and academic performance: evidence from the National Longitudinal Study of Adolescent Health. Economics of Education Review, 29(5), 751-759

Rivkin, S. G., Hanushek, E. A., \& Kain, J. F. (2005). Teachers, schools, and academic achievement. Econometrica, 73(2), 417-458

Solomon, J., \& George, C. (1996). Defining the caregiving system: toward a theory of caregiving. Infant Mental Health Journal: Official Publication of the World Association for Infant Mental Health, 17(3), 183-197

Sorrenti, G., Zölitz, U., Ribeaud, D., Eisner, M. (2020). The causal impact of socio-emotional skills training on educational success. CESifo Working Paper 8197

Subrahmanyam, K., Kraut, R. E., Greenfield, P. M., \& Gross, E. F. (2000). The impact of home computer use on children's activities and development. The Future of Children, 10(2), 123-144

Taylor, B. M., Frye, B. J., \& Maruyama, G. M. (1990). Time spent reading and reading growth. American Educational Research Journal, 27(2), 351-362

Todd, P. E., \& Wolpin, K. I. (2007). The production of cognitive achievement in children: home, school, and racial test score gaps. Journal of Human Capital, 1(1), 91-136

Todd, P. E., \& Wolpin, K. I. (2003). On the specification and estimation of the production function for cognitive achievement. Economic Journal, 113(485), F3-F33

Veenhoven, R. (1984). Conditions of happiness. Dordrecht (Holland): D. Reidel Publishing Company

Zavodny, M. (2006). Does watching television rot your mind? Estimates of the effect on test scores. Economics of Education Review, 25(5), 565-573 